\title{
Does humility facilitate Knowledge Sharing? Investigating the role of humble knowledge-inquiry and response
}

Moffett, S., Anand, A., \& Walsh, I. (2019). Does humility facilitate Knowledge Sharing? Investigating the role of humble knowledge-inquiry and response. Journal of Knowledge Management, 23(6), 1218-1244. https://doi.org/10.1108/JKM-06-2018-0353

Link to publication record in Ulster University Research Portal

\section{Published in:}

Journal of Knowledge Management

Publication Status:

Published (in print/issue): 12/08/2019

DOI:

10.1108/JKM-06-2018-0353

\section{Document Version}

Author Accepted version

\section{General rights}

Copyright for the publications made accessible via Ulster University's Research Portal is retained by the author(s) and / or other copyright owners and it is a condition of accessing these publications that users recognise and abide by the legal requirements associated with these rights.

\section{Take down policy}

The Research Portal is Ulster University's institutional repository that provides access to Ulster's research outputs. Every effort has been made to ensure that content in the Research Portal does not infringe any person's rights, or applicable UK laws. If you discover content in the Research Portal that you believe breaches copyright or violates any law, please contact pure-support@ulster.ac.uk. 
"This is the peer reviewed version of the following article: Moffett, S., Anand, A., \& Walsh, I. (2019). Does humility facilitate Knowledge Sharing? Investigating the role of humble knowledgeinquiry and response. Journal of Knowledge Management, which has been published in final form at [https://doi.org/10.1108/JKM-06-2018-0353]. This article may be used for non-commercial purposes in accordance with Wiley Terms and Conditions for Use of Self-Archived Versions."

\title{
Does humility facilitate knowledge sharing? Investigating the role of humble knowledge- inquiry and response
}

\begin{abstract}
Despite the strong focus on virtues as moral excellence in organizations, humility is little recognized in the management literature and less so in the literature surrounding knowledge sharing (KS). Despite efforts to foster KS amongst employees in firms, the effectiveness of this process dilutes to the dyadic relationship between the knowledge seekers and providers in an organizational context. This conceptual paper investigates the role of humility in the KS process in dyadic activity. We undertake an exploratory investigation to address gaps found in the literature. We identify several individual propensities that help predict humility towards sharing knowledge from seeker (humble knowledge-inquiry) and provider perspectives (humble response). Drawing insights from psychology, history, religion, current events, and management literature, we propose a new conceptual process model of KS with humility as a key variable to consider. Our work highlights several promising directions for future research.
\end{abstract}

Keywords: Knowledge Sharing, Humility, Humble knowledge-inquiry, Humble response

\section{Introduction}

Knowledge is a critical resource in economies (Nonaka \& Takeuchi, 1995) and one of the few assets that tends to grow when shared (Quinn, 1996). For organizations to capitalize on this asset, it needs to be shared amongst employees (Brcic \& Mihelic, 2015) to transform individual 
knowledge into organizational knowledge (Foss et al., 2010). Furthermore, while working in firms, people often face complex or ambiguous challenges, requiring the exchange or sharing of knowledge which leads to knowledge creation and innovation (Jones \& Mahon, 2012; Zhou \& Li, 2012), team creativity (Kessel et al., 2012), sustainable competitive advantage (Alavi \& Leidner, 2001; Ardichvili, Page, \& Wentling, 2003), and organizational success (Smith, 2001; Wang et al., 2014). Knowledge sharing is often a corner stone in the knowledge management strategy of many firms (Riege, 2005). However, although employees interact and communicate with, and depend on, others for work-related knowledge, not everyone in every situation is willing to share their knowledge (Anand and Walsh, 2016) and not sharing knowledge has been considered an unethical practice in many organizations (Panda, 2012, Baskerville \& Dulipovici 2006). The literature on Knowledge Sharing (KS) has investigated many antecedents of KS e.g. Razmerita, Kirchner, \& Nielsen (2016) from an individual perspective e.g., motivation (Ipe 2003), attitude (Bock et al., 2005), self-efficacy (Kankanahalli, et al., 2005), tie strength (Levin $\&$ Cross, 2004), trust and norms of reciprocity, (Chiu et al.,2006; Wasko \& Faraj, 2005), culture at the individual level (Mueller, 2015) and so on. However, very little evidence exists on the construct of humility and how it could foster KS. Humility is considered an ethical value in individuals (Jennings et al, 2005), an ethical requirement for a manager (Argandona, 2017) and one of the ethical duties of a leader (Caldwell et al., 2017), but still, it appears to be neglected, or at least not highlighted, in the business world as a chief virtue (Argandona, 2015). Therefore, while being widely accepted as a virtue, humility has received little organizational attention (Frostenson, 2015) especially in the field of KS. This begs the following questions: In a dyadic one to one relation, has humility a significant role in the KS process between a knowledge seeker and a knowledge provider? What individual and organizational specificities, if any, facilitate humble knowledge seeking and humble knowledge providing?

This paper undertakes an exploratory investigation to answer these questions, attempting to theorize the construct of humility as an antecedent to KS, drawing its sources from research fields that are tangential to management. Specifically, we call upon two concepts related to humility that are emerging in the literature - "humble inquiry" (originally coined by Schein, 2013) and "humble response" (Leach \& Ajibade, 2016) - in a dyadic network of KS. We investigate if there is a reciprocal relationship between these two concepts, and the factors that may moderate or 
mediate the effectiveness of humility in the KS process. We propose a new model of KS where humility is highlighted as an essential component.

Our paper is structured as follows. First, we describe our methodological and systematic approach to the literature. Second, we investigate the literature on KS, highlighting the dyadic relationship between provider and recipient, and the emergence of the concept of humility in this research domain. We then investigate humility as a concept in the broader literature. Next, we define "humble inquiry" and "humble response," and propose different KS scenarios before focusing on one such scenario through a process model of KS with humility. Finally, we discuss our contributions, the limitations of our work and future research avenues.

\section{Methodology}

Undertaking a systematic literature review requires a methodological approach and defined keyword protocol to identify texts related to humility.

As we found few documents that combined the study of KS and the term 'humility' and no existing suitable framework, we had to draw information from very diverse literatures. Therefore, in the present work, we applied a narrative overview approach (Green et al., 2006; de Geofroy and Evans, 2017). A narrative overview synthesizes the findings of the literature retrieved from searches in databases, hand searches, and authoritative texts (Green et al., 2006) and combines many pieces of information into a readable format (Green et al., 2006; Ferrari, 2015). Our findings are summarized below.

To identify the relevant theoretical foundation, including empirical models and conceptual studies around humility, we conducted a systematic literature search. We drew on literature extracted through a list of diverse keywords, starting with 'humility' combined with 'knowledge sharing' and expanding into keywords such as ('humility' and 'business'), ('humility' and 'organization'), ('humility' and 'management'), ('humility' and 'knowledge management') and, eventually, 'humble inquiry' and 'humble response'. We started the search using the Scopus database but also undertook complementary searches on Google Scholar, using the same keyword protocol as applied to the Scopus database. Documents were selected based on the following criteria: (1) the topic of humility, humble inquiry, and humble response that appeared in books, journals and conference papers (2) studies focusing on organization, dyadic, group and individual 
levels (3) humility addressed in broader disciplines of management and business (4) papers that explicitly address humility in knowledge management and KS literature. After careful investigation of all articles highlighted by our search, and of some additional articles cited by first source papers, we eliminated those that duplicated across the two databases and those that were irrelevant to our study. This resulted in a compilation of 44 articles that we retrieved, read and analysed (see Appendix 1).

To guide our reading and understanding, we split the 44 papers into three categories, namely literature based on conceptual viewpoints, those with empirical analysis (containing qualitative and/or quantitative data), and review papers. We also identified the research focus of each article as outlined in Appendix 1. Key to the systematic literature review was focus on the concept of humility, the emergence of humility in KS and possible theoretical gaps.

\section{Knowledge-sharing (KS) and Humility}

In this section, we first define and explain the process of KS from an organizational, individual and interpersonal perspective. This leads us to highlight humility as an individual characteristic with possible significant importance in the KS process.

\subsection{Explaining $K S$}

Knowledge sharing is one of the core activities of knowledge management (Zhang and Jiang, 2015). KS between employees, within and across teams, allows organizations to exploit and capitalize on knowledge-based resources (Wang and Noe, 2010; Ismail et al., 2009). KS involves knowledge-donating and knowledge-collecting (Van den Hooff \& De Ridder, 2004; De Vries et al.,2006). Knowledge-donating is an individual's willingness to share while and knowledgecollecting is to consult, adopt, and accept intellectual capital and know-how (Lin, 2007; De Vries et al., 2006). Knowledge can be shared at various levels, for instance, one-to-one (from an individual to another, e.g., Anaza \& Nowlin 2016), one to many (from an individual to a group e.g., Connelly and Zweig 2015), many to one (from a group/organization to an individual e.g., Cerne et al. 2017) or many to many levels (from a group/organization to another group/organization e.g., Connelly et al. 2012). Although KS is context specific which varies in terms of definition and process (Sergeeva and Andreeva, 2016), in this paper we are specifically 
interested in the one-to-one level of the KS process. Hence we define KS as "an exchange of knowledge between two individuals: one who communicates knowledge and one who assimilates it (Paulin and Suneson, 2012 p. 83).

$\mathrm{KS}$ can occur in various circumstances and it is mainly driven by individual characteristics, interpersonal relations, or situational demands (Zhang and Jiang, 2015). Many researchers have investigated it from different perspectives, e.g., individual (Judge \& Bono, 2001; Zhang \& Jiang, 2015), interpersonal (e.g., Brcic \& Mihelic, 2015; Chowdhury, 2005; Mooradian et al., 2006; Wu et al., 2007), and organizational (e.g., Kovacic et al., 2006; Liebowitz, 2003; Nelson et al., 2006). In this paper, we are specifically interested in the individual and interpersonal perspectives, while taking into consideration the organizational environment and reflecting on key antecedents of KS to include (i) individual providers' characteristics (e.g., Judge and Bono, 2001), (ii) interpersonal characteristics (e.g., Chowdhury, 2005; Mooradian et al., 2006; Wu et al., 2007) and (iii) organizational characteristics (e.g., Liebowitz, 2003; Nelson et al., 2006).

From an individual perspective, Brcic \& Mihelic (2015) categorized the factors contributing to $\mathrm{KS}$ as intrapersonal (e.g., employee motivation and willingness) and interpersonal (e.g., the working relationship between co-workers). Considering interpersonal factors, communication between employees is critical and inter-individual and team relationships are based on how people communicate (Barker \& Camarata, 1998; Jones, 2004i) with individual communication styles contributing to KS: for example, extrovert communication style predicts $\mathrm{KS}$ attitudes in different work-related teams (De Vries et al., 2006). From a situational perspective, knowledge sharing can happen under various circumstances as identified by Bartol and Srivastava (2002). They identify four important approaches for individuals to share knowledge: contribution of knowledge to organizational databases; sharing knowledge in formal interactions within or across teams or work units; sharing knowledge in informal interactions with individuals; and sharing knowledge within communities of practice, which are voluntary forums of employees formed to discuss a topic of interest.

From an interpersonal perspective, KS involves communication, interaction and exchange of skills, expertise, and information between two or more people. It implies actively communicating what one knows to others (Van den Hooff \& de Ridder, 2004) and for KS behavior, it requires the involvement of at least two parties (Zhang \& Jiang, 2015). Furthermore, collaboration and 
interpersonal relationships amongst individuals are essential for collaborative inquiry and KS (Reynolds, 2016). KS depends on interdependence between workers (Anand \& Walsh, 2016) and in the process of knowledge seeking, individuals engage in communicating in their daily routines, through meetings, conversations, and other forms of communication (Weick, 1979). We refer to communication as human interaction through oral conversations and the use of body language while asking, inquiring or reciprocating. KS requires dynamic interaction (Shariq, 1999) and the involvement of a minimum of two parties (dyad) (Zhang and Jiang, 2015). Furthermore, for knowledge sharing to occur, dyadic setting should exist yet there is a dearth of studies that attempt to understand dyadic KS behavior (Pan et al., 2014). In a KS process, a seeker and provider (as components of a dyad) are essential and the effectiveness of the knowledge share depends on the quality of interpersonal communication between participants (Barker and Camarata, 1998). Furthermore, KS depends on the relationship stance between employees (Brcic $\&$ Mihelic, 2015), and the quality of formal and informal conversations (Davenport \& Prusak, 1998). Conversations are not "limited to a merely additive back and forth exchange of information ... [they] can also afford the generation of new knowledge, since each remark can yield new meaning as it is resituated in the evolving context of the conversation" (Cook \& Brown, 1999, p.393). Conversations (when positive) help create a shared experience (Dixon, 1997); build trust and strengthen the relationships between the participants (Harkins, 1999), and are a prerequisite for effective knowledge sharing (Szulanski, 1996). Furthermore, according to Schein, (2013) building relationships between humans is a complex process, with willingness and curiosity considered as missing factors in most conversations. He further suggests that what we ask and the way we ask, defines a trusting relationship, which in turn facilitates better communication and ensures collaboration to accomplish a task (Schein, 2013).

From an organizational perspective, KS may occur spontaneously or be formally facilitated in organizations. Ford and Chan (2003) argue that for companies to gain competitive advantage through KS, an appropriate culture and environment must be in place. Furthermore, many studies have found that KS is strongly related to organizational culture (Issa \& Haddad, 2008; Yang, 2007; Al-Alawi, 2005; Fahey and Prusak, 1998) and the cultural values of individual employees (Jennex, 2006; Hutchings and Michailova, 2004; Hofstede, 2001; Pfeffer and Sutton, 2000). Organizational culture influences not only the successful achievement of KS, but also knowledge-workers' morale and productivity (Lai \& Lee, 2007; Ruppel \& Harrington, 2001a; 
Carayannis, 1998). Organizational culture that supports informal and formal KS (Suppiah \& Sandhu, 2011), and that provides incentives to do so (Wang \& Noe, 2010; Wang et al., 2014), increases the chances of successful KS. From an organizational perspective, senior managers' actions and leaders' supportive behavior also influence KS. According to Carmeli et al., (2013), supportive leadership behavior is directly and indirectly related to KS. On the other hand, according to Owens et al., (2013), humble people make the most effective leaders and are more likely to be high performers in both individual and team settings.

The literature generally argues that employee relationships are based on trust, self-efficacy, reciprocity, and similar characteristics. (Wang \&Noe, 2010). In a dyadic network, the nature of social ties is important and depends on the frequency of interaction and the closeness of the relationship (Naif-Marouf, 2007) while being arrogant or self-focused can impair relationship quality (Peters et al., 2011). The greatest impact on an organization requires workers to establish a deep connection to better understand the knowledge-giver's thoughts (Brcic \& Mihelic, 2015). Ichijo \& Nonaka (2007) believe that "good conversations are the cradle of social knowledge in any organization" as positive conversational routines and interaction patterns enhance relationship building while traits such as defensive arguing or unequal turn-talking (Ellinor \& Gerard, 1998), prevent KS (Mengis \& Eppler, 2008). Employees who communicate with each other frequently and/or have a strong emotional attachment are more likely to share knowledge than those who communicate infrequently or are emotionally detached (Naif-Marouf, 2007).

While seeking knowledge, we communicate and interact, which may change the course of our actions. Individuals have different needs, desires, and goals that help them in choosing behaviors that will bring the desired results (Krok, 2013). This implies that the person who needs knowledge may decide what communication or conversational approach is best suited to start the engagement with co-workers for knowledge seeking. People willing to share their knowledge will expect others to reciprocate in the same way for mutual benefit and to achieve both individual and organizational goals (Lin, 2007; Adler and Kwon, 2002). If people who have rich knowledge yet tend not to share it with co-workers or seekers, see humility in others, this may encourage them to become more willing to engage in the KS process, humble people tend to offer more help to those in need than less humble people (LaBouff et al., 2012). Therefore, we propose that the 
initial step to forming a positive and strong relationship with co-workers may begin with humble conversations. When an individual seeks knowledge, the KS interaction between seeker and provider depends on the seeker's learning attitude - whether the knowledge-seeker is perceived as modest, open-minded, and humble; or hubristic, arrogant, and pretentious; this interaction depends on the quality of the seeker-provider relationship (Zhang and Jiang, 2015). Furthermore, researchers suggest that humble individuals may act as social nodes that reinforce positive social relationships in a group (Kruse et al., 2014; Zhang and Jiang, 2015) and both tacit and explicit knowledge are easier to transfer through strong ties (Reagans and McEvily, 2003). The elements summarized above lead us to investigate if humility could be a characteristic that can help the frequency of dyadic interactions to better build relationships for KS.

\subsection{Emergence of the concept of humility in the KS literature}

The concept of humility is under-studied in the field of KS but has been emerging in recent years as a new construct of interest. We identified four works on this subject in Scopus and Google Scholar databases, e.g. Zhang and Jiang (2015), Mallasi and Ainin (2015), Zhang and Sundaresan, (2010) and Dezdar (2017).

Zhang and Jiang (2015) argue that in a dyadic situation, if knowledge-providers wish to increase self-efficacy or authority, they prefer knowledge-seekers to approach them respectfully and humbly, with a willingness to listen and learn, rather than with an attitude of hubris and arrogance. These authors highlight two important factors that impact KS: the seeker's attitude and the seeker-provider relationship. If the seeker demonstrates a learning attitude (being modest, open-minded, and humble) then the provider is more willing to share. Conversely, if the seeker's attitude is arrogant and pretentious, then the provider may be reluctant to share. These authors also propose that good relationships and trust increase provider willingness to share, but they fail to provide evidence on how relationships are built. We propose that gratitude is an important element in building relations and increasing humility among others: if the seeker receives the expected response, they should express gratitude, which helps develop the seekerprovider relationship. Zhang and Jiang (2015) suggest that managers in firms should build a culture that encourages employees to seek knowledge and that a match between the seeker's and provider's professional competencies can help build relationships. Managers should create a 
climate of trust to facilitate KS. Mallasi and Ainin (2015) investigate KS in the academic environment, proposing that this is a social interaction, facilitated by non-monetary factors such as the enjoyment of helping, reputation, self-efficacy, interpersonal trust, and humility. They define humility as the lack of feeling of superiority, arrogance, and haughtiness of a person toward others (p. 3). They suggest everyone should be treated with respect, gentleness, kindness, and forgiveness and that high humility might promote KS. They investigate scholar humility and general humility. Humility can easily be recognized in scholars when they admit their shortcomings and their struggle to overcome these (Crigger \& Godfrey, 2010). A scholar is a knowledge-seeker or learned person who has much knowledge in a particular area (MerriamWebster, 2013). Therefore, to become a scholar, one should continuously seek knowledge through learning, and so should lack arrogance and over-confidence (Ghosh, 2002). In the same context, Dezdar (2017) suggested that humility is one of the factors that encourages individuals to share knowledge in an academic setting. In her studies, using a student sample set, it was found that humility is positively related to $\mathrm{KS}$ behavior and strongly influences individuals to share knowledge with others. In her study she claims that individuals who hold more knowledge tend to be humbler. Furthermore, humility proved to be a non-monetary factor (we infer to this as intrinsic motivation) in knowledge sharing behavior. Zhang and Sundaresan (2010) identify that the knowledge-recipient may be humble or arrogant, with different propensities for learning characterized by different learning-inhibition cost functions. A humble knowledge-worker is more willing to learn and will not be ashamed of reporting their learning, whereas an arrogant knowledge-worker will be more reluctant to learn after expanding their knowledge. When a provider's knowledge level is relatively low, the potential recipients' knowledge level will also be low. These authors suggest that firms should deal with different types of knowledge-recipients (arrogant or humble) when seeking optimal rewards. Other researchers have suggested that KS depends on cooperative relationships between different organizational members; thus, dyadic cohesiveness is very important in understanding $\mathrm{KS}$, as an individual may show high levels of humility in one facet of life (e.g., academic ability) but not necessarily in another (e.g., social relationships) (Meagher et al., 2015).

\subsection{Humility in the literature}


Since little evidence on humility may be found in the knowledge-management and knowledgesharing literature, we investigate this concept further in the broader literature. Humility has been studied in psychology, theology, ethics, management, etc with its importance highlighted over a decade ago by Exline and Gayer (2004) and Vera and Rodriguez-Lopez (2004). In recent years investigation into the concept of humility has gained momentum (Argandona 2015, 2017, Frostenson, 2015). Understanding humility is important for organizational scholars as it underpins the choice and capacity to approach one's work (and life) from a larger, interdependent perspective that is productive, relational and sustainable (Neilson and Marrone, 2018).

\subsubsection{Defining the characteristics of humility}

Humility is rooted in philosophy and religious beliefs (Hopkin et al., 2014). In psychology and personality studies humility has mostly been addressed from an individual perspective (e.g., Davis et al., 2011; Exline \& Hill, 2012; Landrum, 2011); In business and management, the importance of this construct has recently been highlighted in the literature (e.g., Argandona, 2015; Baldoni, 2009; Frostenson, 2015; Morris et al., 2005) e.g. as a personality trait in managers, as an essential quality for good performance (Argandona, 2015); as a virtue related to the economic, cognitive, and moral aspects of business practice and managerial work (Frostenson, 2015), and as an empowering factor for leadership (e.g., Chiu et al., 2012; Owens et $a l .$, 2013; Baldoni, 2009). Furthermore, it is been studied as a predictor of generosity (Exline \& Hill, 2012), linked to perceived religious beliefs (Hopkin et al., 2014), important to human relationships (Davis et al., 2011; Kruse et al., 2014) and as a personality trait (Chancellor \& Lyubomirsky, 2013; Meagher et al., 2015).

Various authors view humility as a virtue (moral excellence) (Argandona, 2015; Frostenson, 2015; Dwiwardani et al, 2014). According to Chiu et al., (2014), humility is a virtue exists in both Eastern (Ou et al., 2014) and Western philosophies (Owens et al., 2013). Other researchers

address humility as a personal hallmark (Chancellor \& Lyubomirsky, 2013), the accurate assessment of one's abilities (Tangney, 2000; Landrum, 2011; Vera and Rodriguez-Lopez, 2004), a personal orientation (Morris et al., 2015), the opposite to arrogance (Meagher et al., 2015), a personality trait (Owen \& Hekman, 2012), an interpersonal characteristic (Owens et al., 2013), healthy interpersonal relations (Exline, 2008), a willingness to learn from others (Templeton, 1997), a product of egoism (Solomon, 1999), as a trait of forgivingness and patience (Lavelock et 
al., 2014), or a value (Exline \& Geyer, 2004). Chancellor and Lyubomirsky (2013) show that individual humility depends on the situation, and on interpersonal and intrapersonal qualities (e.g., secure, accepting identity; freedom from distortion; openness to new information; otherfocus; and egalitarian beliefs). Less ego predicts humility, gratitude, and forgiveness (Dwiwardani \& Hill, 2014). Owens \& Hekman (2012) investigated why some leaders behave humbly while others do not, showing how leaders can engage followers from developed humility, which in turn can lead to organizational effectiveness.

Humility has been linked with openness and gratitude (Chiu et al., 2012) and with modesty (Davis et al., 2011). It is a desirable personal quality, providing the foundation for moral action in the workplace (Nielsen et al., 2009; Owens \& Hekman, 2012) and for an openness to new ideas and advice seeking (Morris et al., 2005; Owens et al., 2011). Humility lets us go more than halfway to meet the needs/demands of others (Downer, 2009) and contributes to social cohesion and trust creation (Argandona, 2015). It allows the expression of forgiveness, cooperation, and desire to help (Peter et al., 2011) and feelings of personal worth and self-focus (Kruse et al., 2014). For context setting, we adopt the following working definition, considering the facets of KS underpinned by the work of Peter et al., (2011) and Tangney (2000): humility is being modest, respectful, and open-minded rather than arrogant, self-centered, and conceited. Humility can be enduring and dispositional (grounded in personality) or situational (situation- and contextspecific).

\subsubsection{Humble behavior: true humility versus false-pretense humility}

It is sometimes difficult to understand whether humble behavior is genuine or a pretense to obtain something in return. For example, in Western management, there is a growing tendency to examine humility (Chiu et al., 2012); Chinese and other East Asians may appear humbler, but brainwave analysis suggests they can be as proud and arrogant as other cultures (Chen, 2016; Liu, et al., 2018).). Bobb (2013) writes: "while meeting with the boss, your co-worker is differential and winsome, but back in the office, he is full of bluster and condescension for all around him. In public, he wears humility like a comfortable hat, but in private it is all about his self-interest". Some authors suggest that true humility and false-pretense humility can be identified. People with the latter attitude are self-centered and self-congratulating, prone to blame others, slow to 
accept responsibility for mistakes (Bobb, 2013), insecure, people-pleasing, and self-focused. On the other hand, true humility may be witnessed through characteristics such as admitting mistakes, putting others first, talking less and listening more, self-sacrificing, and being keen to serve others (Bobb, 2013; Argandona, 2015; Tangney, 2009).

\subsection{Humility in practice}

Kellogg's includes humility as one of its core values: "We have the Humility and Hunger to Learn." When a firm adopts humility as a core value, this can make employees aware of its importance to its mission (Ferguson, 2013) so encouraging them to contribute and engage in a KS culture. U.S.-based Rockwell Automation also instills a humility culture. It has adopted the widely used leadership style of the "fishbowl," in which senior leaders take questions from junior employees, with unscripted conversations on any topic. Furthermore, leaders routinely demonstrate humility by admitting to employees that they do not have all the answers, and by sharing their own personal journeys of growth and development (Prime \& Salib, 2014). This exhibits how senior employees can express humility by sharing their personal knowledge.

Vera and Rodriguez-Lopez (2004) offer the examples of Odebrecht Organization in Brazil and Mary Kay in the U.S. Odebrecht states that although it is very important for the organizational culture to explicitly recognize the value of humility, it is even more important for leaders at all management levels to clearly model humility. Mary Kay Ash modeled her own firm around respect for the golden rule: "Do unto others as you would have them do unto you." Its culture, structure, and sales system reinforce the need to be humble, and to think about others.

Recruitment practices can help firms identify people willing to engage in KS with humility, making firms more agile and strategic by creating a culture to engage them in being team players. For example, Rick Hensley of Messer Construction used a "personal humility index" to gage humility in potential new hires. His main goal was to find candidates that "see themselves as others see them" (Baldoni, 2009). Lazlo Bock of Google also looks for humility in new hires, not just humility in creating space for others to contribute, but 'intellectual humility': "Without humility, you are unable to learn" (Prime \& Salib, 2014). UPS Corporation's leaders are humble and keen to serve others; there is a knowledge of accountability to others, and to the entire organization, that many companies simply do not have because their leaders are focused on themselves rather than on their people (Goleman, 2013). 


\section{Proposal of a new model}

Combining the literature on KS and on humility leads to the two concepts of humble knowledgeinquiry and humble response, which have started emerging in broad literature but have not been properly defined nor investigated in depth in relation to $\mathrm{KS}$. We attempt to fill this void. We propose different KS scenarios and introduce a new conceptual model of the KS process facilitated by humility in both knowledge seekers and providers.

\subsection{Humble knowledge-inquiry and humble response}

A humble person is more likely to activate others' motivation to share knowledge than a hubris person (Zhang and Jiang, 2015). If the communication approach from a knowledge-seeker is offensive/abusive, disrespectful, commanding, or authoritative, the provider will be reluctant to share knowledge, or might share partial knowledge or hoard knowledge. If a seeker's communication or inquiring approach is humble, the provider will be more inclined to share knowledge. Therefore, to nurture the KS process, it appears essential for knowledge-seekers to adjust their actions toward humility and to align their behavior accordingly (Zhang \& Jiang, 2015); we name this process humble knowledge-inquiry. Furthermore, humility is viewed as an interpersonal stance that is other-oriented rather than self-focused, marked by the ability to restrain egotism (Davis et al., 2011, Davis et al., 2015). So, in this context, when the knowledge seeker adopts humble inquiry, the knowledge provider is inclined to share with humble response. On the other hand, a knowledge-holder, though sometimes vested with authority or power as they retain some knowledge, may respond and share knowledge with a humble attitude; we name this process humble response.

In the literature, we identified two variables that appear to facilitate humble knowledge-inquiry and response, humility may be perceived as having two facets: situational and dispositional. The situational facet is linked to specific situations and rather opportunistic; the dispositional facet is determined by personality and values (Peterson \& Seligman, 2004; Tangney, 2000, 2002). In the same way, humble inquiry is driven by either the demands of the work situation or by personal disposition and values. Humble inquiry is mostly an interpersonal characteristic (Argandona, 2015); variables like openness (Chancellor \& Lyubomirsky, 2013; Davis et al., 2013; Morris et 
al., 2005), patience (Argandona, 2015), learning orientation (Owens et al., 2012), gratitude (Davis et al., 2011; Kruse et al., 2014), and non-arrogance (Landrum, 2011), curiosity (Schien, 2009a), sincerity (Davis et al.,2013), low self-esteem (Exline \& Geyer, 2004), honesty (Ashton \& Lee, 2008) may be considered as essential (Figure 2). Schein (2013), the first to coin the term "humble inquiry", suggests that organizations should create a climate in which people display, through asking genuine questions, an interest in others so that they will want to tell the truth (Schein, 2013). Humble inquiry helps the knowledge-seeker obtain help and advice and build healthy relationships.

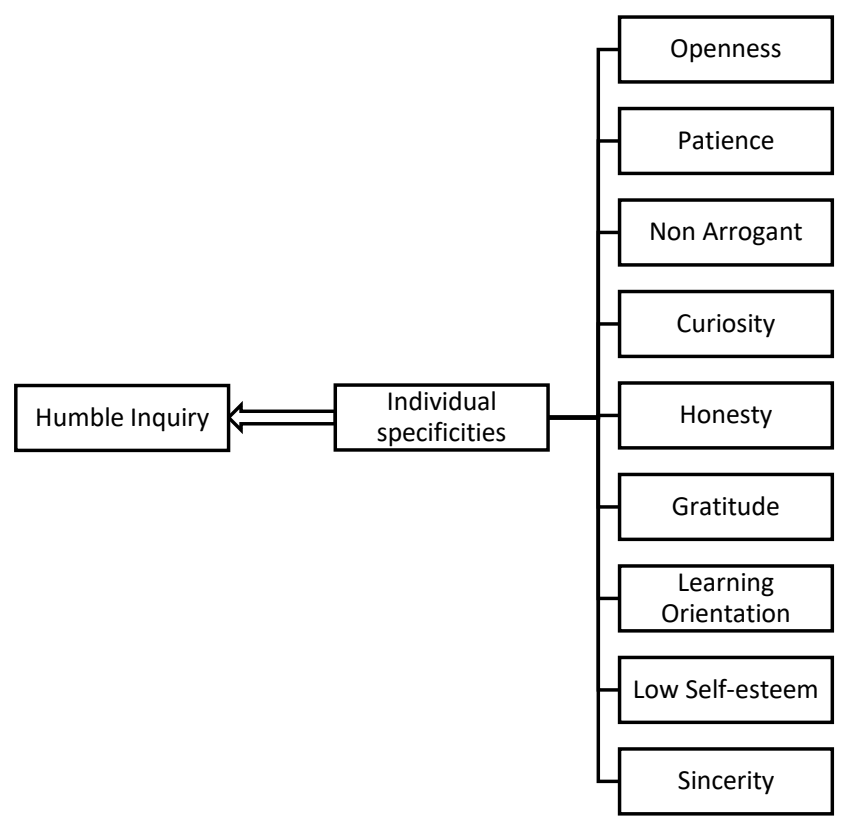

Figure 1: Individual specificities that facilitate humble knowledge-inquiry

Humble response, on the other hand, is more of an intrapersonal characteristic. At the dispositional level, variables found to influence humble-response behavior are generosity (Exline \& Hill, 2012), greed avoidance (Davis et al., 2011), modesty (Chancellor \& Lyubomirsky, 2013), empathy (Davis et al., 2013; LaBouff et al., 2012; Peters et al,2011), low ego (Vera \& Rodrigues-Lopez, 200), transcendence (Oc et al., 2014; Exline et al., 2004), appreciation (Morris et al. 2005;Tengney 2000), self-improvement (Owens et al., 2013) and low arrogance (Rowatt et al. 2006) (Figure 3). 


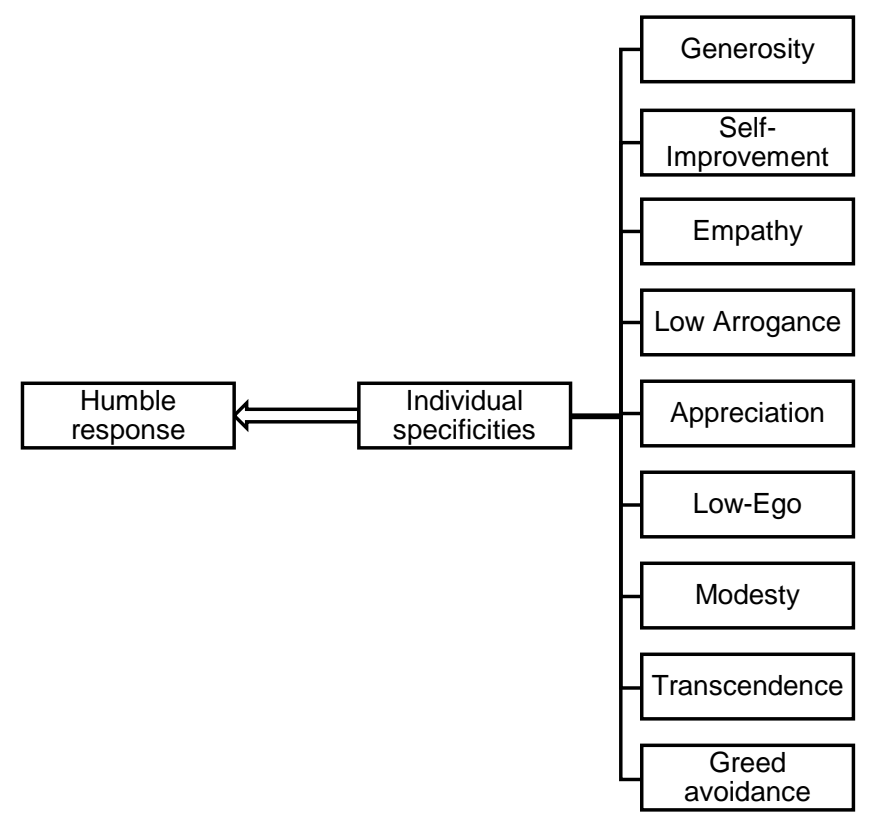

Figure 2: Individual specificities facilitating humble response

\begin{abstract}
Although individual specificities may facilitate humble knowledge inquiry and humble response and induce intrinsic motivators to behave humbly (Deci \& Ryan, 1987), the literature also suggests that extrinsic organizational factors may also influence individuals to develop humble behavior (Ferguson, 2013; Vera and Rodriguez-Lopez, 2004). Furthermore, organizations have embraced humility through various methods, for example in the mission statement, as a core organizational value (Ferguson, 2013) or as part of a nurtured organizational culture. Embracing humility at the organizational level was found to increase employee participation in humble behavior (Ou et al, 2014; Vera and Rodriguez-Lopez, 2004). Organizations may also use recruitment methods to identify humble individuals during recruitment practice, which helps firms in promoting individuals as humble team players and increases the learning capability amongst others (Prime \& Salib, 2014; Baldoni, 2009). Within organizations, it has also been highlighted that supportive and humble leaders help individuals to follow humility (Nielson and Maronne, 2018) (see figure 3).
\end{abstract}




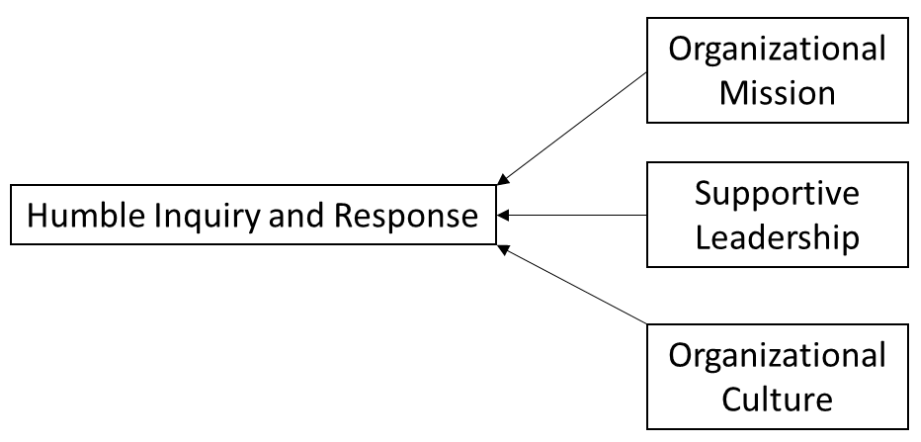

Figure 3: organizational specificities facilitating humble inquiry and response

\subsection{Humility and possible KS scenarios}

Whilst the personal specificities of both recipient and provider are crucial in KS, a knowledge holder may choose to share knowledge irrespective of those seeking it. If this is done humbly, it can encourage recipients to welcome shared knowledge; we name this process humble knowledge-offer. During the sharing process, we propose three possible scenarios.

In scenario 1 (Figure 4), the knowledge-provider acts as the initiator in offering the knowledge. For instance, altruism may be one of the provider's top-ranked values, derived from the intrinsic enjoyment of helping others (Kankanhalli et al.,2005 b), making them humble enough to share knowledge. At the same time, extrinsic motivations (e.g., rewards, recognition, reciprocal benefits and self-esteem) may encourage the provider to develop humble behavior. An extrinsic motivation would be a monetary reward for KS offered by the organization (Beer \& Nohria, 2000; Hall, 2001b), which could lead to a better overall outcome (Kankanhalli et al., 2005 a). For instance, according to Lin (2007), the KS costs for an individual (e.g. time taken, mental effort, etc.) provide potential gains in receiving organizational rewards. If we are motivated by our own needs and values, we are intrinsically motivated; if we are motivated by someone or something else, we are extrinsically motivated (Deci \& Ryan, 1980). Furthermore, in this scenario the provider may offer knowledge when someone appears in need or when asked to do so by a third party or may volunteer to give away knowledge whether or not it is needed (at that particular 
time). In this case, the recipient is not an active seeker; they receive the knowledge passively following the provider's initiative.

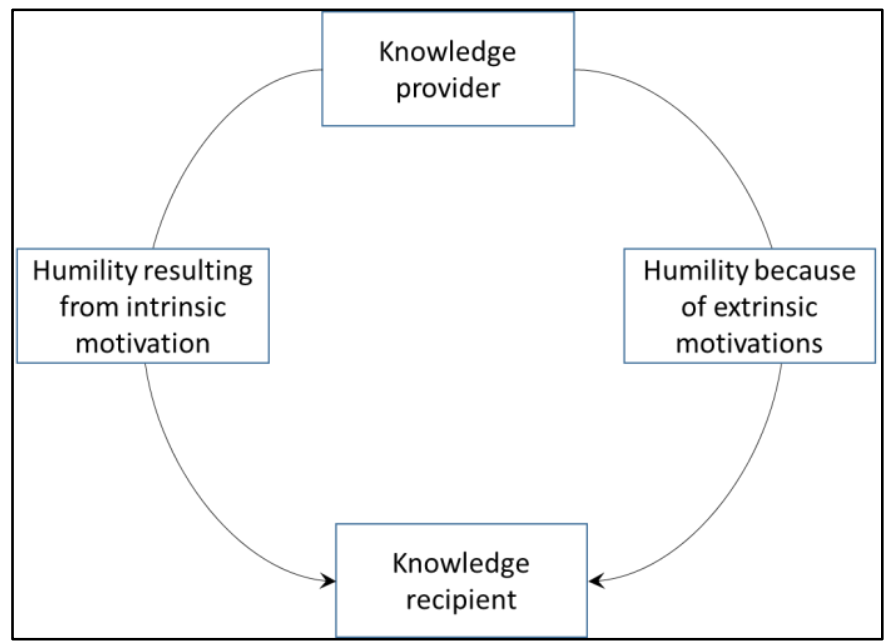

Figure 4: Scenario 1-provider as initiator (humble knowledge-offer)

In scenario 2 (Figure 5), the knowledge-recipient is the initiator in seeking knowledge. Beyond the extrinsic motivation of obtaining much-needed knowledge through a humble attitude, the seeker has values (e.g., being down to earth, modest, polite, and altruistic) that may intrinsically motivate them to be humble. They may also observe co-workers seeking knowledge with humility and be inclined to replicate this attitude. Also, if the seeker has received knowledge passively through a humble provider, this might make the seeker reciprocate with humility when actively seeking knowledge.

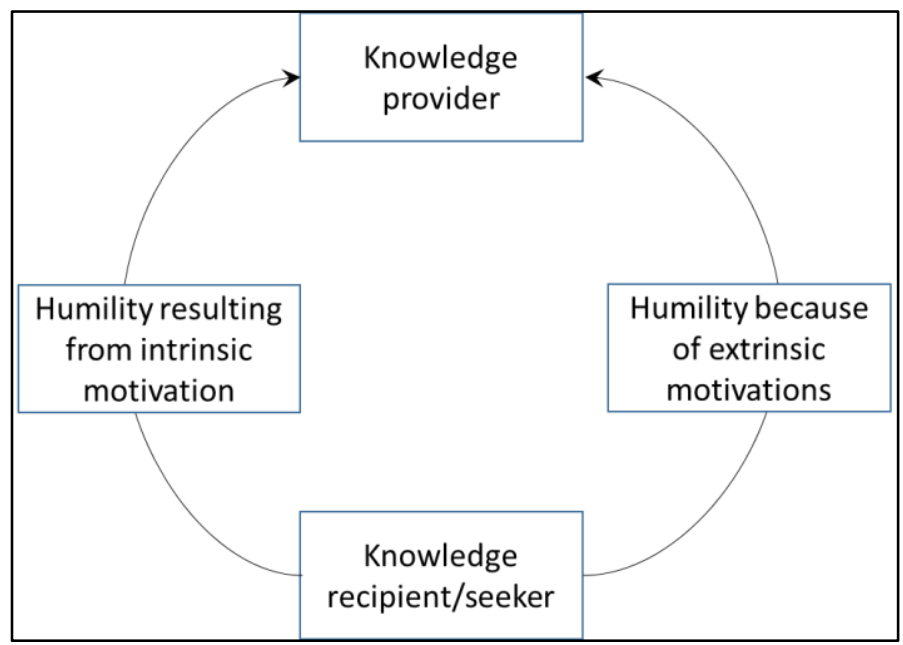


Fig 5: Scenario 2-recipient as initiator (humble knowledge-inquiry)

In scenario 3 (Figure 6), there is a two-way initiative (from both seeker and provider) toward KS; both may be intrinsically and/or extrinsically motivated to ask, share or receive with humility. Both parties may engage in KS with humility because intrinsically they enjoy the process and find it inherently interesting (Deci \& Ryan, 1980) and are satisfied by enhancing their knowledge self-efficacy or confidence in their ability to provide knowledge that is useful to the organization (Lin, 2007, Constant et al.,1994). They may also be driven by a goal that extrinsically motivates them (Deci \& Ryan, 2000). Here, extrinsic benefits could be reputation (Bock et al., 2005), feedback potentially leading to active participation (Donath, 1999) and reciprocity (Wasko \& Faraj, 2005).

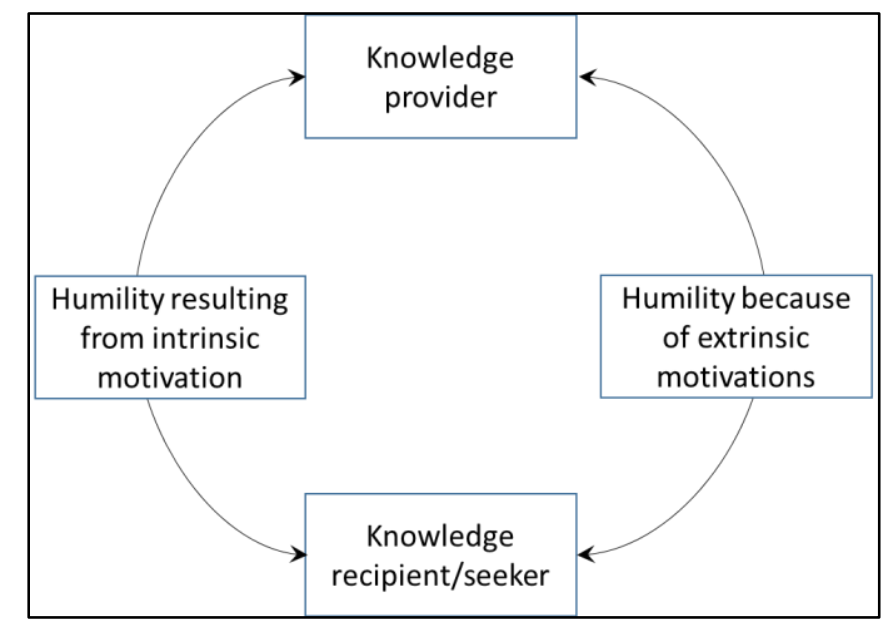

Figure 6: Scenario 3-both provider and recipient as initiators (reciprocity)

Bassett-Jones and Lloyd's (2005) found that intrinsic motivators outweighed motivators linked to financial inducement of employees' willingness to contribute ideas. Furthermore, Law et al., (2017) assert that intrinsic motivation had significant positive effects on knowledge sharing compared to extrinsic motivation (e.g. Bock and Kim 2002; Lucas and Ogilvie, 2006).

The above scenarios are applicable in the context of sharing tacit or explicit knowledge. However, these scenarios hold good only in a work-place setting that involves face-to-face communication: interactions and behaviors may differ in different contexts like, for instance, online or virtual environments. 
We highlight in the scenarios described above, that humility can be an intrinsic motivator (dispositional character) and/or an extrinsic motivator (driven by reward or influenced by others). We outline situations when the seeker or provider are actively seeking/providing and/or passively seeking/providing knowledge; seekers/providers' dispositional characteristics (intrinsic motivation) may make them always remain humble in any situation or they may observe others

doing the same and develop a humble attitude (seeker and provider) or organizational rewards may drive them to develop a humble attitude (seeker and provider). Humility as a virtue is of intrinsic character (e,g, Argandona 2013), and extrinsic motivation of humility in business complements the normative and consequentialist idea of why humility is relevant in today's business (Frostenson, 2015, Pg. 97). Therefore, even though the literature argues that individuals should possess the virtue of humility intrinsically (e.g. Frostenson, 2015, Argandona, 2015), extrinsic motivators may also encourage people to embrace and develop humble attitudes.

\subsection{Sharing with humility: proposed model}

In today's highly competitive corporate world, few people are prepared to offer their knowledge freely (Anand and Walsh, 2016); thus, KS is often induced by employees actively seeking knowledge from others. Based on the literature, humble inquiry by the knowledge-seeker at work is more likely to induce a positive and humble response by the knowledge-provider, irrespective of their dispositions. We propose a four-phase model of KS with humility (Figure 7) and define each phase accordingly. 


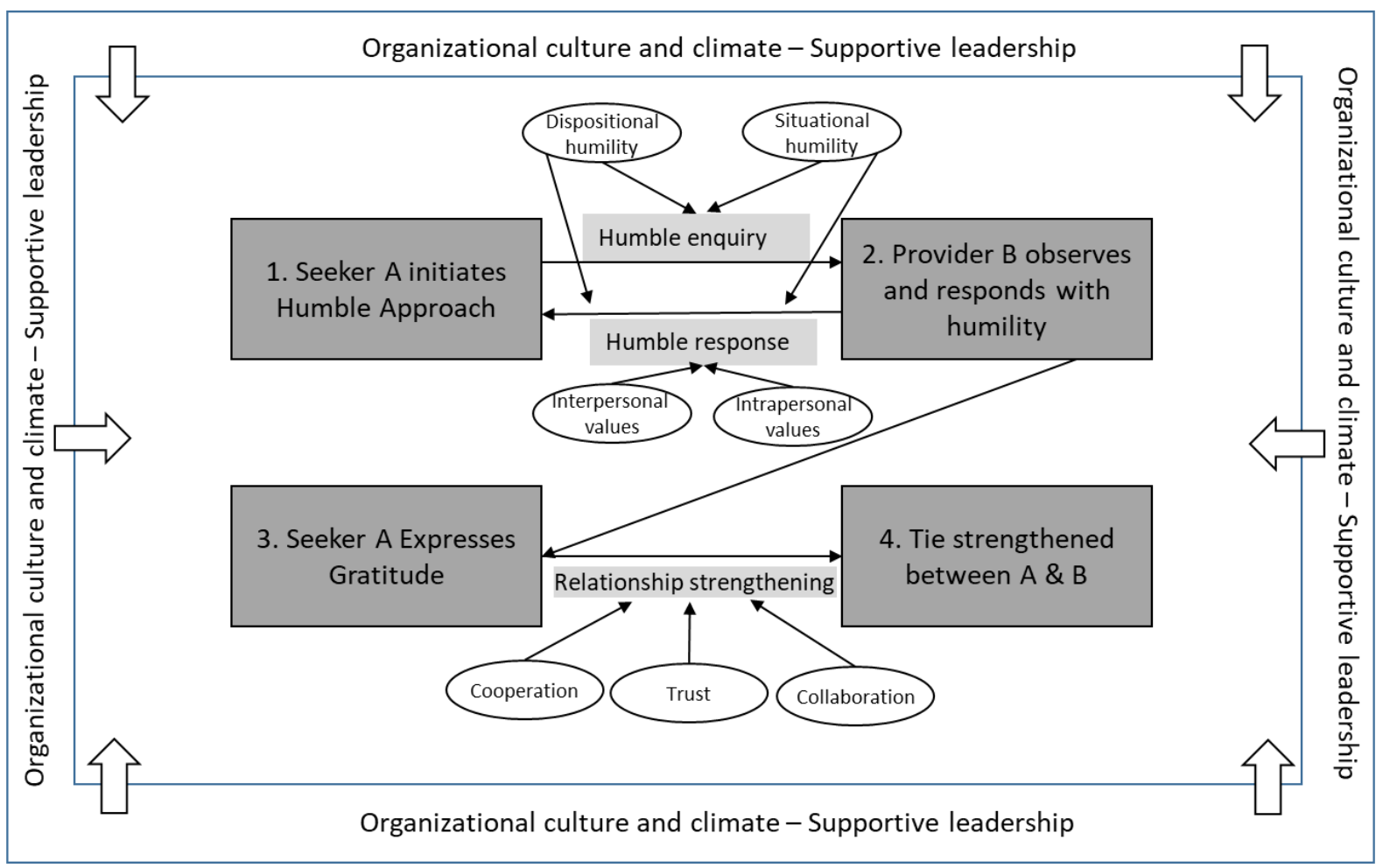

Figure 7: Model explaining KS with humility

Phase-1 (humble approach): Some scholars argue that dispositional humility is a trait present only in knowledge providers (Zhang and Jiang, 2015). However, the knowledge-seeker, after identifying the source of knowledge (provider), may adopt humble inquiry to seek specific questions or close knowledge gaps. Humility from an individual can induce generosity amongst other individuals (Exline and Geyer, 2004) and individuals who have a humble attitude tend to receive more support from others (Exline, 2012). Hence a humble approach from the knowledge seeker can increase the chances of the provider sharing with humility. Furthermore, humility has been described as a character strength (Peterson \& Seligman, 2004), valued by people (Dahlsgaard et al.,2005; Exline and Geyer, 2004), and related to multiple pro-social outcomes (Chancellor \& Lyubomirsky, 2013). Therefore, we would propose that this first phase of the KS process is optimized if the knowledge-seeker is of a humble disposition (Landrum, 2011) and their humility is not situationally induced or pretentious (Zhang and Jiang, 2015). 
During Phase-2 (humble response), the provider observes the seeker's approach and communication method. If the approach is humble, the provider will be more inclined toward generosity and might respond with humility. Concerning the provider, some researchers suggest that sharing one's knowledge is pro-social in nature, and there may not be any reward for such acts. Employees who are pro-socially inclined tend to be more interested in benefiting others (Bolino and Grant, 2016). The term 'humility response' outlines that if the provider has knowledge that could be useful to someone else (whether actively seeking or not), they will donate it generously i.e., humility can be a dispositional quality among the providers (Zhang and Jiang, 2015) or, if they do not know the answer to a specific query of the provider, they will openly express their ignorance with humility, perhaps suggesting to the seeker what needs to be done to obtain the information (e.g. alternative information source). Zhang and Jiang (2015) identify that a sincere, modest, or humble approach motivates others to respond similarly. Some authors highlight that in business, humility is a trait found in some knowledge-providers, predicting ethical business practices (Ashton \& Lee, 2008), willingness to help (LaBouff et al., 2012), and cooperation (Hilbig et al., 2012). Furthermore, individuals tend to develop humble responses from the motivation that they get from leaders, who are humble and supportive and who create positive workplace behaviors (Owens \& Hekman, 2012). It has been highlighted that humble leaders empower followers (Ou, 2012).

During Phase-3 (gratitude), gratitude complements the humble response. The literature shows that gratitude is associated with better relationship satisfaction, increases pro-social behavior, reduced self-focus, promotes humility (Kruse et al., 2014) and less negative affect following major life changes (Wood et al., 2008). In our proposed model, if the relationship between seeker and provider should continue in future subsequent interactions, the seekers expression of gratitude would promote and increase humility, pro-social behavior in the provider and build better relationship satisfaction (e.g. Kruse et al., 2014; Peter et al., 2011; Bartlett \& DeSteno, 2006). Therefore, we would propose that gratitude may have a strong impact on subsequent provider's humility, which in turn will help in building a stronger relationship between seeker and provider and nurture further KS. 
Phase-4 (Tie strengthening): Although several dispositional and situational variables influence whether one person helps another (Penner et al., 2005), helping one another in times of need is a cornerstone of quality human relationships (Labouff et al., 2012). Humility interactions facilitate strong ties, create trust, and increases trustworthiness (Ou et al., 2014, Sousa \& van Dierendonck, 2015), cooperation (Exline and Geyer, 2004; Peter et al., 2011), collaboration (Schein, 2013; Vera and Rodriguez-Lopez, 2004, Ou et al., 2014, Lin 2007), quality and strong relations (Peter et al, 2011; Dezdar, 2017). If KS has taken place between the seeker and provider, gratitude may further help in strengthening relationships (Kruse et al., 2014). A social bond develops between the two, making the sharing process more effective. Humble behavior can also help repair broken relationship and builds a strong bond between people (Davis et al, 2013; Worthington et al., 2017). This fourth phase completes a dyadic closed loop of KS but may also serve as an example to other actors. Furthermore, humility combined with gratitude may build strong relations, because the two are mutually reinforcing (Kruse et al., 2014).

For the four phases to be effective, organizations play an essential role in facilitating humility practice among individuals, since humility in organizations is a competitive advantage, it helps strategic leaders and firms to achieve outstanding performance (Vera and Rodriguez-Lopez, 2004. pg. 398). For instance, adopting humility as a mission and as a core organizational value engages employees to value humility (Ferguson, 2013), and humility as part of organizational culture can increase pro-social behavior among individuals (Owen and Heckman, 2012; Vera and Rodriguez-Lopez, 2004). Leaders who represent organizations, support humility in individuals through empowering climates (Ou et al., 2014), and supportive leadership behaviors (Owens et al.,2013), which help individuals develop humility (Nielson and Maronne, 2018).

On the other hand, from an individual perspective, both seeker and provider may have interpersonal and intrapersonal values that could be prerequisites for humble behavior. Chancellor and Lyubomirsky (2013) show that individual humility depends on the situation, and on interpersonal and intrapersonal values (e.g., secure, accepting identity; freedom from distortion; openness to new information; other-focus; and egalitarian beliefs). Furthermore, prosocial interpersonal values that facilitate humble behavior include modesty, respect, honesty, orientation towards others, willingness to ask for help or accept criticism, the ability to recognize others' strengths, and the tendency to feel awe before the sacred (Bollinger, 2010; Davis et al., 
2011). Intrapersonal values in both seeker and provider may include self-knowledge and virtue (Argandona, 2015), possession of an accurate or moderate view of self (e.g., Bollinger, 2010; Tangney, 2000), and the ability to assess personal characteristics relative to others (Tangney, 2002) rather than inflating one's self-evaluation.

Our model contributes to Zhang and Jiang's (2015) investigation of KS. These authors suggest that characteristics of the knowledge seeker affect the knowledge sharers' willingness to share. Viewing others as humble should facilitate greater commitment to the KS process (Davis et al., 2011). The added component of gratitude in a dyadic situation could encourage humble behavior from the provider and help build stronger relationships (e.g. Kruse et al., 2014).

\section{Conclusion}

This study provides a theoretical contribution to knowledge management, and in particular knowledge sharing, research. The growing attention on KS as a critical success factor of knowledge management (Dezdar, 2017), motivated this paper to understand whether humility, often considered as an ethical value in individuals, is in fact an important factor for KS in a dyadic relation and what individual and organizational specificities, if any, facilitate humble knowledge seeking and humble knowledge providing. Through an extensive review of diverse literatures, our findings highlight that there are various factors that help both individuals and organizations to adopt different facets of humility in the process of KS. We found that the knowledge seeker role is essential in the KS process, as the seeker's humble approach can motivate the knowledge provider to share their knowledge and to do so through humble response. Humility is driven by individual dispositions and situational constraints, which may lead to true or false-pretense humble behavior.

Furthermore, this study also found that there are three important organizational factors, namely culture, mission and leadership, which can support effective KS between individual employees. We unmask how humble inquiry and response can promote the creation of strong social ties and relationship strengthening in a dyadic KS process. Our work shows that humility may be a prerequisite for KS, and so needs to be, not only embraced at the individual level, but also promoted within organizations. 


\section{Limitations of the study}

This paper, along with the proposed model, has limitations but also opens many avenues for future research and contributes to the current body of literature concerning humility and KS. Humility remains a relatively new, poorly understood, and often-neglected construct in organizational research (Oc et al., 2015) and even more so in the KS context. One obstacle to an empirical approach to studying humility is the basic conceptual question of what humility actually is (Meagher et al.,2015) and, consequently, there is a need for researchers to seek greater consensus in their definitions of humility, particularly in the context of KS. One challenge that remains is to fully understand the intention behind a seemingly humble attitude. Might it be falsepretense humility, with selfish, opportunistic, politically motivated, or self-promotional motives? A person may choose a humble approach based on the situation, but the success depends on how the knowledge-seeker's behavior is interpreted by the knowledge-provider. This further depends on the provider's traits or history of KS activities with a given seeker and requires further investigation. In our proposed model, we considered mostly one possible type of KS, where knowledge is recognized as needed by the knowledge-seeker. Yet KS may also be initiated by a knowledge-provider toward recipients who are not actively seeking knowledge. Hence these recipients might not recognize the importance and usefulness of the knowledge that is shared with them (e.g., when a professor teaches passive students, who do not want to learn). In this case, a different process model would have to be proposed.

Our model helps firms better understand the KS process at the one to one level as well as better facilitate and guide it. However, several caveats should be highlighted. First, humility behavior may depend on the cultural context and individual perceptions; for instance, humble behavior may appear as part of the existing norms in some cultures and exceptional and rare in others. Since most existing research on which our model is based is set in the Western part of the world, the model we proposed may need some adaptation to be applied in Eastern cultures. Also, the provider might feel that being too humble risks the seeker becoming a threat. KS depends on willingness of individuals to share with others and, in some instances, needs to be effectively encouraged and facilitated. Similarly, humility could be encouraged and facilitated but forcing humility could also be a violent act (Kerr, 2017). Thus, KS and humility may be highly dependent on the context in which knowledge is voluntarily shared or requested. 


\section{Study implications and future research}

This study provides practical implications for both managerial and organizational practices. For instance, to boost KS practices, firms could aim to nurture humble environments and promote humility through the appointment of humble managers. Managers/leaders often act as knowledge-providers; employees, who rate their managers as humble feel more engaged and less likely to quit, more committed to the leader's vision, and more trusting and receptive to their ideas (Feder \& Sahibzada, 2012). Thus, humble leadership and empowering leadership can help firms to induce humility among employees, at organizational level (Owens, 2013). Furthermore, adopting humility as a core value in the organizational mission and goals can attract employees who would be more inclined and motivated to work with humility.

However, some dilemmas in sharing knowledge with others that are faced by some individuals might only be resolved through rewards (Cabrera and Cabrera, 2002). Our proposed humility model may help reduce reward mechanisms and increase citizenship behavior among employees (Anand and Walsh, 2016; Lam and Lambermont-Ford, 2010).

Creating a humble environment as part of organizational culture can improve and encourage collaboration, versatility, learning, and inventiveness, thus promoting $\mathrm{KS}$ and nurturing competitive advantage. However, researchers suggested that in order to do so, there is a need to encourage a humble culture in firms (Owens, 2013, Baskerville \& Dulipovici 2006). An enlightening example from the Maori people of New Zealand highlights a practice named, kia mahaki - meaning being humble, sharing knowledge, and seeking to empower the community through research (Pipi, et al.,2004). Thus, in firms, humility could become an opportunity as it helps provide confidence and allows employees to develop strong relationships. Furthermore, to encourage proactive knowledge sharing among employees, managers need to consider the importance of identifying and rewarding the firm's "primum movens" (i.e., the first person willing to share with humility, setting an example, and motivating others to do so) (Anand and Walsh, 2016).

Furthermore, investigation into the role of humility in manager-employee relations as an enabler and facilitator of KS can be useful. For a knowledge seeker, the provider's knowledge will have positive impact for learning and to build strong relations. Expressed humility reflects a person's 
tendency to approach interpersonal interactions with a strong motive for learning through others (Owens et al., 2013). Humility appears an important ethical characteristic not only for leaders but also for employees, allowing both groups to work well individually and as teams. A humble employee is aware of personal limitations and is willing to accept and give help as needed. As humble people do not seek social dominance, they are more willing to learn from others and compliment others in their accomplishments (Exline, 2008).

Our study provides an understanding for leaders to engage employees with humble attitude, which may in turn encourage employees to seek required work knowledge. It could be useful to research leaders' possible influence on employees toward the development of humble behaviors in KS. Research on whether adopting humility as a core organizational value changes organizational members' attitudes would also be interesting to develop. Furthermore, mediating factors such as collective humility, shared leadership (Chiu et al., 2016) have also emerged and could motivate researchers to investigate further.

Although our model is conceptual, it could be built upon with scale development and/or through experimental studies. One could investigate whether or not humility is, in fact, always possible in KS activities, whatever the context, e.g., researchers could experimentally manipulate situations that make humility difficult to practice (i.e., conflict, recognition, and power struggle), thus enhancing differences in humble behavior (Davis et al., 2011).

Furthermore, our model could help investigate the role of humility in building social relationships, which have been receiving increasing attention in organizational scholarship (Owens et al., 2013). Researchers have used various tools, e.g., self-report (Lee \& Ashton, 2004; Meager et al., 2015) and social comparisons (Rowat et al., 2002) to assess humility, but a detailed multi-method approach could help to better understand the humble behavior. Applying structural equation modeling could be considered. For example, an experimental design to test the proposed model could be set up to verify whether our theory holds true. This could lead to new developments of supporting attributes: Humility is a valuable, scarce resource and people who claim to be very humble may seem to be bragging, something truly humble people would not do (Davis et al., 2015). Future research is needed to verify whether humility is, indeed, always connected to positive outcomes in KS and in which contexts, if any, humility could be illadvised. 
From a social exchange perspective, interpersonal reciprocity and trust are antecedents in KS, e.g. Liao (2008) and perceived supervisor support and supervisors' encouragement of KS increase employees' knowledge exchange with each other as well as their perceptions of the usefulness of KS (Cabrera et al., 2006; Kulkarni et al., 2006). So, we address humility as another variable in our study and this can encourage researchers to study it from different theoretical perspective (e.g theory of reasoned action, social exchange theory and theory of learned behavior).

Recognition and appreciation can increase humility among employees working in firms. As Newman (1982, p. 283) pointed out, humility requires a severe appraisal of oneself combined with a reasonably generous appraisal of others. Humble people appreciate others' positive recognition of their worth, strengths, and contributions (Morris et al., 2005). For example, receiving organizational recognition, positive feedback on knowledge shared, or feedback on how the knowledge was shared helps co-workers and the company facilitate KS efficacy. When others recognize the value of one's knowledge, individuals may gain an enhanced self-perception of competency, credibility, and confidence (Stasser \& Titus, 2003), which increases the likelihood that they will share their knowledge with others. Such appreciation is grounded in the legitimate understanding of their strengths, thus removing any need for entitlement or dominance over others (Peterson \& Seligman, 2004). Thus, a study into whether recognition practices induce humility behavior among employees towards KS would be profitable.

We highlight humble inquiry and response as fairly new concepts to be considered in the context of KS. Whether the sharing process cycle continues in a longer run through continued humble inquiry and response under any given situations still needs to be investigated. For instance, if any conflict occurs between seeker and provider, will it induce some non-humble behavior from the provider? Does gratitude increase relationship satisfaction and reduce self-focus (Kruse et al., 2014)? These are some of the questions that could be addressed by future research. More broadly, the model we proposed could be tested at different time intervals: one could investigate whether humility in individuals changes over a period of time or remains consistent, and due to what factors.

People practicing religious faiths should also be aware of the role of humility. For example, the Bible provides a description of what humility is not: "Haughty eyes and a proud heart, the lamp of the wicked, are sin" (Proverbs 21:4) and "Do nothing out of selfish ambition or vain conceit, 
but in humility consider others better than yourselves" (Philippians 2:3). In the Bible, humility is being courteously respectful of, and gentle, kind, and forgiving toward, all others; it is the opposite of aggressiveness, arrogance, boastfulness, and vanity. It might also be interesting to investigate whether individuals' practice of religious faiths influences humble behavior in KS.

Our highlight of different types of humility (true humility versus false pretense humility) and the different corresponding facets of this construct (dispositional versus situational) may help toward its modeling in further research. Furthermore, our work suggests that, in the context of KS, humility may need to be approached from both the knowledge-seeker's and the knowledgeprovider's perspectives. To help achieve this in further research, we have highlighted the various individual specificities that may help toward humble knowledge-inquiry and humble response.

In the context of virtual teams, where face to face communication is limited, as highlighted by Ardichvili et al., (2003), people in virtual communities share knowledge due to moral obligation; they assume that knowledge belongs to their organization and not to themselves. Furthermore, these authors suggest that organizational culture and personal networks may influence KS. It could be interesting to study whether the knowledge seeker(s) computer-mediated communications (for instance, through video conferences) induce some changes in our model and investigate if humility does have a role to play in virtual settings.

\section{References}

1. Adler, S. P. and Kwon, S. W. (2002) Social capital: prospects for a new concept, Academy of Management Review, 27, 1, pp. 17-40.

2. Al-Alawi, A. I. (2005) The practice and challenges of knowledge management in financial sectors in Bahrain, Asian Journal of Information Systems, 4, 1, pp. 101-107.

3. Alavi, Maryam, and Dorothy E. Leidner (2001):. "Review: Knowledge Management and Knowledge Management Systems: Conceptual Foundations and Research Issues.” MIS Quarterly 25, no. 1 pp.107-136 
4. Algoe, S. B., \& Haidt, J. (2009). Witnessing excellence in action: The "other-praising”, emotions of elevation, gratitude, and admiration. The Journal of Positive Psychology, 4, $105-127$.

5. Algoe, S. B., Gable, S. L., \& Maisel, N. C. (2010). It's the little things: Everyday gratitude as a booster shot for romantic relationships. Personal Relationships, 17, 217233

6. Anaza, N.A. and Nowlin, E.L., (2017). What's mine is mine: A study of salesperson knowledge withholding \& hoarding behavior. Industrial Marketing Management, 64, 1424.

7. Ardichvili, A., Page, V. and Wentling, T. (2003), "Motivation and barriers to participation in virtual knowledge-sharing communities of practice', Journal of Knowledge Management, Vol. 7 No. 1, pp. 64-77

8. Anand, A. \& Walsh, I. (2016), "Should Knowledge be Shared Generously: Tracing Insights from Past to Present by Describing a Model", Journal of Knowledge Management, Vol :20

9. Andrew Kerr (2017). "The Humility Imperative: Why the Humble Leader Wins In an Age of Ego", Lulu Publishing Services

10. Argandona, A. (2015). Humility in Management. Journal of Business Ethics, 132(1), 6371. http://doi.org/10.1007/s10551-014-2311-8

11. Argandoña, A(2017), Humility and Decision Making in Companies. IESE Business School Working Paper No. 1164-E. Available at SSRN: https://ssrn.com/abstract=2969748

12. Ashton, M. C., \& Lee, K. (2008). The prediction of Honesty-Humility related criteria by the HEXACO and Five-Factor models of personality. Journal of Research in Personality, $42,1216-1228$.

13. Aven, B. (2012). Dyadic Information Transfer: A Network Study of Organizational Information Spread. Retrieved from http://repository.cmu.edu/cgi/viewcontent.cgi?article=2403\&context=tepper 
14. Baird, L., \& Henderson, J. C. (2001). The knowledge engine. San Francisco: BerrettKoehler

15. Baldoni, John, (2009), "Use Humility to Improve Performance", Harvard Business Review, Retrieved from https://hbr.org/2009/11/use-humility-to-improve-perfor

16. Barker, R. T., \& Camarata, M. R. (1998). The role of communication in creating and maintaining a learning organization: Preconditions, indicators, and disciplines. Journal of Business Communication, 35, 443-467.

17. Bartlett, M. Y., \& DeSteno, D. (2006). Gratitude and Prosocial Behavior: Helping when it costs you. Psychological Science, 17, 319-325.

18. Bartol, K. M., \& Srivastava, A. (2002). "Encouraging KS: the role of organizational reward systems". Journal of Leadership \& Organizational Studies, 9(1), 64-76.

19. Baskerville, R., \& Dulipovici, A. (2006). The ethics of knowledge transfers and conversions: Property or privacy rights? Proceedings of the Annual Hawaii International Conference on System Sciences, 7(C), 1-9.

20. Bassett-Jones, N. and Lloyd, G.C. (2005), "Does Herzberg"s motivation theory have staying power?", Journal of Management Development, Vol. 24 No. 10, pp. 929-943.

21. Beer, M., \& Nohria, N. 2000. Breaking the code of change. Boston, MA: Harvard Business School Press

22. Bobb, J David (2013). "Five ways to tell if humility is real or fake". Retrieved on June 2016, from http://www.foxnews.com/opinion/2013/11/16/five-ways-to-tell-if-humility-isreal-or-fake.html

23. Brcic, Ž. J., \& Mihelič, K. K. (2015). KS between different generations of employees: an example from Slovenia. Economic Research-Ekonomska Istraživanja.

24. Bolino, Marc and Grant, Adam. and. (2016). The Bright Side of Being Prosocial at Work, and the Dark Side, Too: The Academy of Management Annals, $0(0), 1-72$.

25. Burke, M.E (2011) "KS in emerging economies", Library Review, Vol. 60 Iss: 1, pp.5 14 
26. Caldwell, C., Ichiho, R., \& Anderson, V. (2017). Understanding level 5 leaders: the ethical perspectives of leadership humility. Journal of Management Development, 36(5), 724-732.

27. Cabrera, A. and Cabrera, E.F. (2002), "Knowledge-sharing dilemmas", Organization Studies, Vol. 23 No. 5, pp. 687-710.

28. Cameron and Spreitzer (2011) Oxford Handbook of Positive Organizational Scholarship, Oxford University Press, New York, NY;

29. Cameron, K. S., Dutton, J. E., \& Quinn, R. E. (2003). Positive organizational scholarship. San Francisco: Berrett-Koehler.

30. Carayannis, E. G. (1998) The strategic management of technology learning in project/program management: the role of extranets, intranets and intelligent agents knowledge generation, diffusion and leveraging, Technovation, 18, 11, pp. 697-703.

31. Carmeli, A., Gelbard, R., \& Palmon, R. (2013). Leadership, creative problem solving capacity, and creative performance: The importance of KS. Human Resource Management, 52, 95-121

32. Cerne, M., Hernaus, T., Dysvik, A., \& Škerlavaj, M. (2017). The role of multilevel synergistic interplay among team mastery climate, knowledge hiding, and job characteristics in stimulating innovative work behavior. Human Resource Management Journal, 27(2), pp.281-299.

33. Chancellor, J., \& Lyubomirsky, S. (2013). Humble Beginnings: Current Trends, State Perspectives, and Hallmarks of Humility. Social and Personality Psychology Compass, 7(11), 819-833. doi:10.1111/spc3.12069

34. Chen, S (2016). Chinese tradition of humility and self-effacement disguises people's true emotions, research suggests. Retrieved on October 2016 from http://www.scmp.com/news/china/article/1985661/chinese-tradition-humility-and-selfeffacement-disguises-peoples-true 
35. Chiu, C., Hsu, M., \& Wang, E. (2006). Understanding knowledge sharing in virtual communities: An integration of social capital and social cognitive theories. Decision Support Systems, 42(3), 1872-1888. https://doi.org/10.1016/j.dss.2006.04.001

36. Chiu, T. S., Huang, H. J., \& Hung, Y. (2012). The Influence of Humility on Leadership: A Chinese and Western Review. International Conference on Economics, Business and Marketing Management, 29, 129-133.

37. Chowdhury, S. (2005). The role of affect- and cognition-based trust in complex KS. Journal of Managerial Issues, 17(3), 310-326

38. Connelly, C.E. and Zweig, D., (2014). How perpetrators and targets construe knowledge hiding in organizations. European Journal of Work and Organizational Psychology, 24(3), pp.479-489.

39. Connelly, C. E., Zweig, D., Webster, J., \& Trougakos, J. P. (2012). Knowledge hiding in organizations. Journal of Organizational Behavior, 33(1), pp.64-88.

40. Constant D, Kiesler S and Sproull L (1994) What's mine is ours, or is it? A study of attitudes about information sharing. Information Systems Research 5(4), 400-421.

41. Cook, S. D. N., \& Brown, J. S. (1999). Bridging epistemologies: The general dance between organizational knowledge and organizational knowing. Organization Science, 10(4), 381-400.

42. Crigger, N., \& Godfrey, N. (2010). "The importance of being humble". Advances in Nursing Science, 33(4), 310

43. Dahlsgaard, K., Peterson, C., \& Seligman, M. E. (2005). Shared virtue: The convergence of valued human strengths across culture and history. Review of General Psychology, 9, 203-213.

44. Davenport, T. H., \& Prusak, L. 1998. Working knowledge: How organizations manage what they know. Boston: Harvard Business School Press; Drucker, 
45. Davis, D. E., Hook, J. N., Worthington, E. L., Van Tongeren, D. R., Gartner, A. L., Jennings, D. J. (2011). Relational humility: Conceptualizing and measuring humility as personality judgment. Journal of Personality Assessment, 93(3), 225-234.

46. Davis, D. E., Rice, K., McElroy, S., DeBlaere, C., Choe, E., Van Tongeren, D. R., \& Hook, J. N. (2015). Distinguishing intellectual humility and general humility. The Journal of Positive Psychology, 9760 (April), 1-10.

47. Davis, D. E., Worthington, E. L., Hook, J. N., Emmons, R. a., Hill, P. C., Bollinger, R. a., \& Van Tongeren, D. R. (2013). Humility and the Development and Repair of Social Bonds: Two Longitudinal Studies. Self and Identity, 12(1), 58-77.

48. De Vries, R. E., Van den Hoff, B. and de Ridder, J. A. (2006) Explaining KS: the role of team communication styles, job satisfaction, and performance beliefs, Communication Research, 33, 2, pp. 115-135.

49. Deci, E. L., \& Ryan, R. M. (1980). The empirical exploration of intrinsic motivational processes. In L. Berkowitz (Ed.), Advances in experimental social psychology (Vol. 13), pp. 39-80). New York: Academic Press.

50. Dezdar S, (2017) "Promoting knowledge sharing in academic environments using nonmonetary factors", Library Review. 66(8/9) 595-611

51. Dixon, N. (1997). The hallways of learning. Organizational Dynamics, 25, 23-34

52. Donath, J.S., 1999. Identity and deception in the virtual community. In: Smith, M., Kollock, P. (Eds.), Communities in Cyberspace. Routledge, New York

53. Downer, Rosemarie T (2009), “The Self Scarred Church”, Xulon Press,

54. Dwiwardani, C., \& Hill, P. (2014). Virtues develop from a secure base: Attachment and resilience as predictors of humility, gratitude, and forgiveness. Journal of Psychology, 42(1), 83-90. http://doi.org/0091-6471/410-730

55. Ellinor, L., \& Gerard, G. (1998). Dialogue: Rediscover the transforming power of conversation. New York: Wiley 
56. Emmons, R. A., \& McCullough, M. E. (2003). Counting blessings versus burdens: An experimental investigation of gratitude and subjective well-being in daily life. Journal of Personality and Social Psychology, 84, 377-389.

57. Exline, J. J. \& Geyer, A. L. (2004). Perceptions of Humility: A Preliminary Study. Self and Identity, 3, 95-114.

58. Exline, J. J. (2008). Taming the wild ego. In H. A. Wayment \& J. A. Bauer (Eds.), Transcending self-interest: Psychological explorations of the quiet ego (pp. 53-62). Washington, DC: American Psychological Association

59. Fahey, L. and Prusak, L. (1998) The eleven deadliest sins of knowledge management, California Management Review, 40, 3, pp. 265-276.

60. Feder, Zachary \& Sahibzada, Khatera (2014). Turns our humility offers a Competitive Advantage. Retrieved from https://www.entrepreneur.com/article/238328

61. Ford, D. P. and Chan, Y. E. (2003) KS in multi-cultural setting: a case study, Knowledge management Research and Practice, 1, 1, pp. 11-27.

62. Foss, N. J., Husted, K., \& Michailova, S. 2010. Governing KS in Organizations: Levels of Analysis, Governance Mechanisms, and Research Directions. Journal of Management Studies, 47(3): 455-482.

63. Frostenson, M. (2015). Humility in Business: A Contextual Approach. Journal of Business Ethics 138: 91

64. Ghosh, S. (2002). Humbleness as a practical vehicle for engineering ethics education. Paper presented at the Frontiers in Education, 2002. FIE 2002.

65. Goleman, Daniel (2013). The Focused Leader Harvard Business Review, Retrieved at https://hbr.org/2013/12/the-focused-leader

66. Gulati, R. 1995 "Does familiarity breed trust: The implications of repeated ties for contractual choice in alliances." Academy of Management Journal, 38: 85-112.

67. Hansen, M. (1999). The search-transfer problem: The role of weak ties in sharing knowledge across organization subunits. Administrative Science Quarterly, 44(1), 82-111. 
68. Harkins, Phil. (1999). Powerful Conversations: How High Impact Leaders, Communicate. New York: McGraw Hill

69. Harris, T. E., \& Nelson, M.D. (2008). Applied organizational communication: Theory and practice in a global environment. New York: Lawrence Erlbaum.

70. Hilbig, B. E., Zettler, I., \& Heydasch, T. (2012). Personality, punishment, and public goods: Strategic shifts towards cooperation as a matter of dispositional honesty-humility. European Journal of Personality, 26, 245-254

71. Hilbig, B.E., \& Zettler, I. (2009). Pillars of cooperation: Honesty-humility, social value orientations, and economic behavior. Journal of Research in Personality, 43, 516-519.

72. Hofstede, G. H. (2001) Culture's consequences: comparing values, behaviors, institutions and organizations across nations, 2nd ed., Sage Publications, Thousand Oaks, CA.

73. Hopkin, C. R., Hoyle, R. H., \& Toner, K. (2014). Intellectual humility and reactions to opinions about religious beliefs. Journal of Psychology and Theology, 42,50-61

74. Horwitz SK and Santillan C (2012) KS in global virtual team collaboration. Knowledge Management Research \& Practice 10(4), 342-353.

75. Huizinga, R. B. (2016). An Understanding of Humility-Based Leadership Impacting Organizational Climate. Emerging Leadership Journeys, 9(1), 34-44.

76. Hutchings, K. and Michailova, S. (2004) Facilitating KS in Russian and Chinese subsidiaries: the role of personal networks and group membership, Journal of Knowledge Management, 8, 2, pp. 84-94.

77. Ichijō, Kazuo. \& Nonaka, Ikujirō. (2007). Knowledge creation and management: new challenges for managers. Oxford : Oxford University Press

78. Ismail Al-Alawi, A., Yousif Al-Marzooqi, N., \& Fraidoon Mohammed, Y. (2007). Organizational culture and knowledge sharing: critical success factors. Journal of Knowledge Management, 11(2), 22-42.

79. Ichijo K., Nonaka I.(2007) "Knowledge Creation and Management: New Challenges for Managers. New York: Oxford University Press Inc. 
80. Ismail, W. K., Nor, K. M. and Marjani, T. (2009) The role of KS practice in enhancing project success, Interdisciplinary Journal of Contemporary Research In Business, 1, 7, pp. 34-52

81. Issa, R. A. A. and Haddad, J. (2008), Perceptions of the impacts of organizational culture and information technology on KS in construction, Construction Innovation, 8, 3, pp. 182-201.

82. Jennings, L., Sovereign, a., Bottorff, N., Mussell, M. P., \& Vye, C. (2005). Nine ethical values of master therapists. Journal of Mental Health Counseling, 27(1), 32-47. https://doi.org/Article

83. Jones, S. (2004). Putting the person into person-centred and immediate emotional support: Emotional change and perceived helper competence as outcomes of comforting in helping situations. Communication Research, 31, 338-360.

84. Jones, N. B., \& Mahon, J. F. (2012). Nimble knowledge transfer in high velocity/turbulent environments. Journal of knowledge management, 16(5), 774-788.

85. Judge, T. A., \& Bono, J. E. (2001). Relationship of core self-evaluations traits-selfesteem, generalized self-efficacy, locus of control, and emotional stability-with job satisfaction and job performance: A meta-analysis. Journal of Applied Psychology, 86(1), $80-92$.

86. Kankanhalli, A., Tan, B. C., and Wei, K. K. 2005a. "Understanding Seeking from Electronic Knowledge Repositories: An Empirical Study," Journal of the American Society for Information Science and Technology, (56:11), pp. 1156-1166.

87. Kankanhalli, A., Tan, B.C.Y., and Wei, K.K. 2005b. "Contributing Knowledge to Electronic Knowledge Repositories: An Empirical Investigation," MIS - Quarterly, (29:1), pp. 113-143.

88. Kessel, M, Kratzer, J, Schultz, C (2012) 'Psychological safety, KS, and creative performance in healthcare teams `Creativity and Innovation Management, 21, pp. 147-157.

89. Kovacic, A., Bosilj Vuksic, V., \& Loncar, A. (2006). A process-based approach to knowledge management. Economic Research, 19, 53-66. 
90. Krok, E (2013) "Willingness to share knowledge compared with selected social psychology theories, Contemporary Economics, Vol 7, issue 1, Pp. 101-109

91. Kruse, E., Chancellor, J., Ruberton, P. M., \& Lyubomirsky, S. (2014). An upward spiral between gratitude and humility. Social ethics Psychological and Personality Science, $5(7), 805-814$.

92. Kulkarni, U. R., Ravindran, S., \& Freeze, R. (2006). A knowledge management success model: Theoretical development and empirical validation. Journal of Management Information Systems, 23(3), 309-347.

93. Kurtz, C. F., \& Snowden, D. J. (2003). The new dynamics of strategy: Sense-making in a complex and complicated world. IBM Systems Journal.42(3), 462-483

94. LaBouff, J. P., Rowatt, W. C., Johnson, M. K., Tsang, J. A., \& Willerton, G. M. C. (2012). Humble persons are more helpful than less humble persons: Evidence from three studies. Journal of Positive Psychology, 7(1), 16-29. https://doi.org/10.1080/17439760.2011.626787

95. Lai, M. F. and Lee, G. G. (2007) Risk-avoiding cultures toward achievement of KS, Business Process Management Journal.13, 4, pp. 522-527

96. Lam, A. and Lambermont-Ford, J.P. (2010), "Knowledge sharing in organizational contexts: a motivation-based perspective", Journal of Knowledge Management, Vol. 14 No. 1, pp. 51-66.

97. Landrum, R. E. (2011). Measuring dispositional humility: A first approximation. Psychological Reports, 108(1), 217-228.

98. Lavelock, C. R., Worthington, E. L. J., Davis, D. E., Griffin, B. J., Reid, C. A., Hook, J. N., \& Van Tongeren, D. R. (2014). The quiet virtue speaks: An intervention to promote humility. Journal of Psychology and Theology, 42(1), 99-110.

99. Leach, M. M., \& Ajibade, A. (2016). Correlates, and Sequelae of Humility. Handbook of Humility: Theory, Research, and Applications. 
100.Lee, K., \& Ashton, M. C. (2004). Psychometric properties of the HEXACO personality inventory. Multivariate Behavioral Research, 39, 329-358.

101.Levin, D.Z. and Cross, R. (2004), “The strength of weak ties you can trust: the mediating role of trust in effective knowledge transfer", Management Science, Vol. 59 No. 11, pp. 1477-1490.

102.Liang, T.-P., Liu, C.-C., \& Wu, C.-H. (2008). Can Social Exchange Theory Explain Individual Knowledge Sharing Behavior? A Meta Analysis. Icis, 1-18.

103.Liebowitz, J. (2003). A knowledge management strategy for the Jason organization: A case study. Journal of Computer Information Systems, 44(2), 1-5

104.Lin, H.F. (2007) KS and firm innovation capability: an empirical study, International Journal of Manpower, 28, 3-4, pp. 315-332

105.Lin, H.-F. (2007). Effects of extrinsic and intrinsic motivation on employee knowledge sharing intentions. Journal of Information Science, 33(2), 135-149.

106.Liu, Y., Chan, C., Zhao, C., \& Liu, C. (2018). Unpacking knowledge management practices in China: do institution, national and organizational culture matter?. Journal of Knowledge Management.

107.Lucas, L.M. and Ogilvie, D.T. (2006), "Things are not always what they seem: how reputations, culture and incentives influence knowledge transfer", The Learning Organization, Vol. 13 No. 1, pp. 7-24

108. Mallasi, H and Ainin, S (2015), "Investigating KS Behaviour in Academic Environment”, Journal of Organizational Knowledge Management

109. Mansor, Z. D., Mustaffa, M., \& Salleh, L. M. (2015). Motivation and Willingness to Participate in Knowledge Sharing Activities Among Academics in a Public University. Procedia Economics and Finance, 31(15), 286-293. https://doi.org/10.1016/S22125671(15)01188-0 
110.Marcus, B., Lee, K., \& Ashton, M. C. (2007). Personality dimensions explaining relationships between integrity tests and counterproductive behavior: Big five or one in addition? Personnel Psychology, 60, 1-34.

111.McCullough, M. E., Emmons, R. A., \& Tsang, J.-A. (2002). The grateful disposition: A conceptual and empirical topography. Journal of Personality and Social Psychology, 82, $112-127$.

112. Meagher, Benjamin R., Joseph C. Leman, Joshua P. Bias, Shawn J. Latendresse, and Wade C. Rowatt. (2015). "Contrasting Self-Report and Consensus Ratings of Intellectual Humility and Arrogance." Journal of Research in Personality 58:35-45.

113.Mengis J and Eppler MJ. (2008) Understanding and managing conversations from a knowledge perspective: An analysis of the roles and rules. Organization Studies 29: $1287-1313$.

114.Merriam-Webster Online. Merriam-Webster. Retrieved July 1, 2016, from http://www.merriam-webster.com/dictionary/citation

115. Mueller, Julia. (2015). Formal and Informal Practices of Knowledge Sharing Between Project Teams and Enacted Cultural Characteristics. Project Management Journal 46:issue-1, 53-68.

116. Mooradian, T., Renzl, B., \& Matzler, K. (2006). Who trusts? Personality, trust and KS. Management Learning, 37(4), 523-540.

117.Morgan, V. G. (2001). Humility and the transcendent. Faith and Philosophy, 18(3), $307-$ 322

118. Morris, J. A., Brotheridge, C. M., \& Urbanski, J. (2005). Bringing humility to leadership: Antecedents and consequences of leader humility. Human Relations, 58(10), 1323-1350.

119. Naif-Marouf, L. (2007). Social networks and knowledge sharing in organizations: a case study. Journal of Knowledge Management, 11(6), 110-125.

120.Nelson, A., Sabatier, R., \& Nelson, W. (2006). Toward an understanding of global entrepreneurial knowledge management (EKM) practices: A preliminary investigation of 
EKM in France and the U.S. Journal of Applied Management and Entrepreneurship, 11(2), 70-89.

121.Newman, J. (1982). Humility and self-realization. Journal of Value Inquiry, 16(4), 275285

122. Nielsen, R., Marrone, J. A., \& Slay, H. S. (2009). A new look at humility: Exploring the humility concept and its role in socialized charismatic leadership. Journal of Leadership and Organizational Studies, 17(1), 33-42.

123. Nielsen, R., Marrone, J. A., (2018). Humility: our current understanding and its role in Organizaions. International journal of Management Reviews, (00), 1-20.

124.Nonaka I and Takeuchi H. (1995) The knowledge-creating company. How japanese create the dynamics of innovation, New York-Oxford University Press.

125.Oc, Burak; Bashshur, Michael R.; Daniels, Michael A.; Greguras, Gary J.; and Diefendorff, James M., (2015). "Leader Humility in Singapore" Psychology Faculty Research. 17.

126. Ou, A. (2012, August). Building an empowering organization: A study of humble CEOs. Paper presented at the annual meeting of the Academy of Management, Boston, MA

127.Ou, A. Y., Tsui, A. S., Kinicki, A. J., Waldman, D. A., Xiao, Z., \& Song, L. J. (2014). Humble Chief Executive Officers' Connections to Top Management Team Integration and Middle Managers' Responses. Administrative Science Quarterly, 59(1), 34-72.

128. Owens, B. P. (2009). Humility in organizations: Establishing construct, nomological.and predictive validity. In Academy of management best papers proceedings. Briarcliff Manor, NY: Academy of Management.

129. Owens, B. P. (2010). Humility in organizational leadership. Dissertation Abstracts International Section A: Humanities and Social Sciences, 70(8-A), 3223.

130. Owens, B. P., \& Hekman, D. R. (2012). Modeling how to grow: An inductive examination of humble leader behaviors, contingencies, and outcomes. Academy of Management Journal.55(4), 787-818. 
131. Owens, B. P., Johnson, M. D., \& Mitchell, T. R. (2013). Expressed humility in organizations: Implications for performance, teams, and leadership. Organization Science, 24(5), 1517-1538.

132. Owens, B. P., Rowatt, W. C., \& Wilkins, A. L. (2011). Exploring the relevance and implications of humility in organizations. In K. S. Cameron \& G. S. Sprelitzer (Eds.), Handbook of positive organizational scholarship (pp. 260-272). Oxford, UK: Oxford University Press.

133.Paulin, D., \& Suneson, K. (2012). Knowledge Transfer , Knowledge Sharing and Knowledge Barriers - Three Blurry Terms in KM. Electronic Journal of Knowledge Management, 10(1), 81-91.

134.Pan, Y.C. Xu, X. Wang, C. Zhang, H. Ling, J. Lin, (2014) Integrating Social Networking Support for Dyadic Knowledge Exchange: A Study in a Virtual Community of Common Practice, Information and Management 52(1) 61-70

135.Penner, L.A., Dovidio, J.F., Piliavin, J.A., \& Schroeder, D.A. (2005). Prosocial behavior: Multiple perspectives. Annual Review of Psychology, 56, 365-392.

136.Peters, A. S., Rowatt, W. C., \& Johnson, M. K. (2011). Associations between dispositional humility and social relationship quality. Psychology, 2(3), 155-161.

137.Peterson, C., \& Seligman, M. E. P. (2004). Character strengths and virtues: A handbook and classification. Washington, DC: American Psychological Association; New York: Oxford University Press

138.Pfeffer, J. and Sutton, R. I. (2000). "The knowing doing gap: how smart companies turn knowledge into action", Harvard Business School Press, Boston, MA.

139.Pipi, Kataraina,Cram, Fiona, Hawke Rene, Hawke Sharon, Te Miringa Huriwai, Tania Mataki, Moe Milne, Karen Morgan, Huhana Tuhaka and Colleen Tuuta (2004). A Research Ethic for Studying Māori and Iwi Provider Success, Social Policy Journal Document: Issue 23 
140.Prime, Jeanine and Salib, Elizabeth (2014), "The Best Leaders are humble Leaders", Harvard Business Review, Retrived from https://hbr.org/2014/05/the-best-leaders-arehumble-leaders

141.Quinn, J. J. (1996). The role of 'good conversation' in strategic control. Journal of Management Studies, 33, 381-394.

142.Razmerita, L., Kirchner, K., \& Nielsen, P. (2016). What factors influence knowledge sharing in organizations? A social dilemma perspective of social media communication. Journal of Knowledge Management, 20(6), 1225-1246.

143. Reagans, R., \& McEvily, B. (2003). Network structure and knowledge transfer: The effects of cohesion and range. Administrative Science Quarterly, 48(2), 240-268.

144.Reynolds, R. B. (2016). Relationships among tasks, collaborative inquiry processes, inquiry resolutions, and knowledge outcomes in adolescents during guided discoverybased game design in school.

145.Riege, A. (2005). Three-dozen knowledge-sharing barriers managers must consider. Journal of knowledge management, 9(3), 18-35.

146.Rowatt, W. C., Ottenbreit, A., Nesselroade, K. P., \& Cunningham, P. (2002). On being holier-than-thou or humbler-than-thee: A social-psychological perspective on religiousness and humility. Journal for the Scientific Study of Religion, 41, 227 - 237.

147. Rowatt, W.C, Tsang, J.A, Kelly, J, Lamartina, McCullers, B.M and McKinley (2006), A. Associations between Religious Personality Dimensions and Implicit Homosexual Prejudice. Journal for the Scientific Study of Religion.. 45(3): 397-406

148. Ruppel, C. P. and Harrington, S. J. (2001a) Causal ambiguity, barriers to imitation, and sustainable competitive advantage, European Management Journal.22, 6, pp. 714-724.

149.Ryan, R. M., \& Deci, E. L. (2000). Intrinsic and Extrinsic Motivations: Classic Definitions and New Directions. Contemporary Educational Psychology, 25(1), 54-67.

150.Schein, E. (2013). Humble inquiry: the gentle art of asking instead of telling. San Francisco, CA: Berrett—Koehler Publisher, Inc. 
151.Schwartz, S. H., Cieciuch, J., Vecchione, M., Davidov, E., Fischer, R., Beierlein, C., Konty, M. (2012). Refining the theory of basic individual values. Journal of Personality and Social Psychology, 103(4), 663-688.

152. Seigenberg, D. (2004). Humility versus Self-Esteem: Implications for Research and Practice. Most, 29(1).

153.Sergeeva, A., \& Andreeva, T. (2016). Knowledge Sharing Research: Bringing Context Back In. Journal of Management Inquiry, 25(3), 240-261.

154. Shariq, S. Z. (1999). How does knowledge transform as it is transferred? Speculations on the pos- sibility of a cognitive theory of knowledge capes. Journal of Knowledge Management, 3, 243-251

155. Shockley-Zalabak, P. (1995). Fundamentals of organizational communication: Knowledge, sensitivity, skills, values (3rd Ed.). New York: Longman.

156. Sietsma, S. (n.d.). Humility in Leadership - Innovating a Classic Leadership and Governance Interactive Session Humility in Leadership - Innovating a Classic, 1-12.

157.Smith, E. A. (2001). The role of tacit and explicit knowledge in the workplace. Journal of knowledge Management, 5(4), 311-321.

158.Solomon, RC, 1999 “A Better Way to Think About Business: How Personal Integrity Leads to Corporate Success", New York, Oxford: Oxford University Press, Francisco, CA: Jossey-Bass.

159.Sousa, M., \& van Dierendonck, D. (2015). Servant Leadership and the Effect of the Interaction Between Humility, Action, and Hierarchical Power on Follower Engagement. Journal of Business Ethics, 141(1), 13-25. https://doi.org/10.1007/s10551-015-2725-y

160.Stasser, G., \& Titus, W. (2003). Hidden Profiles: A Brief History, Psychological Inquiry, 14, 304-313.

161.Swift, M., Balkin, D.B. and Matusik, S.F. (2010), "Goal orientations and the motivation to share knowledge”, Journal of Knowledge Management, Vol. 14 No. 3, pp. 378-393. 
162. Szulanski, G. (1996) „Exploring Internal Stickiness: Impediments to the Transfer of Best Practice Within the Firme, Strategic Management Journal.Vol 17, No. Winter Special Issue, pp 27-43.

163.Tangney, J. P. (2000). Humility: Theoretical perspectives, empirical findings and directions for future research, Journal of Social and Clinical Psychology, 19, 70- 82.

164.Tangney, J. P. (2002). Humility. In C. R. Snyder \& S. J. Lopez (Eds.). Handbook of Positive psychology (pp. 411-419). Oxford: Oxford University Press.

165.Tangney, J. P. (2009). Humility. In S. J. Lopez \& C. R. Snyder (Eds.), Oxford handbook of positive psychology (2nd ed., pp. 483-490). New York, NY, US: Oxford University Press.

166.Templeton, J. M. (1997). Worldwide laws of life: Two hundred eternal spiritual principles. Radnor, PA: Templeton Press

167. Van den Hooff, B. and De Ridder, J. A. (2004) KS in context: the influence of organizational commitment, communication climate and CMC use on KS, Journal of Knowledge Management, 8, 6, pp. 117-130.

168. Vera, D., \& Rodriguez-Lopez, A. (2004). Strategic virtues: Humility as a source of competitive advantage. Organizational Dynamics, 33(4), 393-408.

169.Wang, S., \& Noe, R. A. (2010). KS: A review and directions for future research. Human Resource Management Review, 20, 115-131.

170.Wang, S., Noe, R. A., \& Wang, Z.-M. (2014). Motivating KS in knowledge management systems a quasi-field experiment. Journal of Management, 40, 978-1009.

171.Wasko, M. M. and Faraj, S. (2000) 'It is what one does: Why people participate and help others in electronic communities of practice', Journal of Strategic Information Systems, vol. 9, pp.155-173.

172.Weick, K. E. (1979). The social psychology of organizing (2nd Ed.). Reading, MA: Addison-Wesley. 
173.Wood, A. M., Maltby, J., Gillett, R., Linley, P. A., \& Joseph, S. (2008). The role of gratitude in the development of social support, stress, and depression: Two longitudinal studies. Journal of Research in Personality, 42, 854-871.

174. Worthington, E. L., Jr., Davis, D. E., \& Hook, J. N. (Eds.). (2017). Handbook of humility: Theory, research, and applications. New York: Routledge/Taylor \& Francis Group.

175.Wu, W. -L., Hsu, B. -F., \& Yeh, R. -S. (2007). Fostering the determinants of knowledge transfer: A team-level analysis. Journal of Information Science, 33(3), 326-339

176. Yang, J. T. (2007) KS: investigating appropriate leadership roles and collaborative culture, Tourism Management, 28, 2, pp. 530-543.

177.Zaid T. Alhalhouli (2015) "Factors Affecting KS Behavior among Stakeholders in Jordanian Hospitals Using Social Networks", International Journal of Computer and Information Technology, Volume 03 - Issue 05 (919-928)

178.Zhang, X, Jiang, J Y, (2015) "With whom shall I share my knowledge? A recipient perspective of KS", Journal of Knowledge Management, Vol. 19 (2), pp.277 - 295

179.Zhang, Z and Sundaresan, S. "Knowledge Markets in Firms: KS with Trust and Signaling" Knowledge Management Research \& Practice Vol. 8 Iss. 4 (2010)

180.Zhou K.Z and Li C.B (2012), "How knowledge affects radical innovation: knowledge base, market knowledge a acquisition, and internal KS. Strategic Management Journal 33 (9), 1090-1102. 


\section{Appendix 1}

\begin{tabular}{|c|c|c|c|c|c|}
\hline Citations & 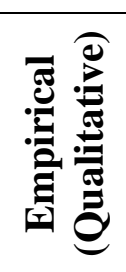 & 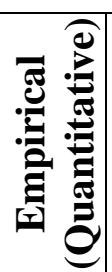 & 苞 & : & Focus Area \\
\hline Argandoña (2015) & & & $\sqrt{ }$ & & Humility in management \\
\hline Argandoña (2017) & & & & $\sqrt{ }$ & Humility in decision making \\
\hline $\begin{array}{l}\text { Ashton and Lee } \\
\qquad(2008)\end{array}$ & & $\sqrt{ }$ & & & Honest-Humility predictions \\
\hline Baldoni (2009) & & & $\sqrt{ }$ & & $\begin{array}{l}\text { Humility improving individual } \\
\text { performance }\end{array}$ \\
\hline Bobb (2013) & & & & $\sqrt{ }$ & Humility as greatest virtue in America \\
\hline $\begin{array}{c}\text { Chancellor and } \\
\text { Lyubomirsky (2013) }\end{array}$ & & & & $\sqrt{ }$ & Interpersonal and Intrapersonal humility \\
\hline Chiu (2012) & & & & $\sqrt{ }$ & $\begin{array}{l}\text { Humble leadership in Chinese and } \\
\text { Western context }\end{array}$ \\
\hline $\begin{array}{l}\text { Criger and Godfrey } \\
(2010)\end{array}$ & & & $\sqrt{ }$ & & Humility and its importance in nursing \\
\hline Davis et al (2011) & & $\sqrt{ }$ & & & Humility as a personality judgement \\
\hline Davis et al (2013) & & $\sqrt{ }$ & & & Personality and relational humility \\
\hline Davis et al (2015) & & $\sqrt{ }$ & & & Intellectual humility and humility \\
\hline Dezdar (2017) & & $\sqrt{ }$ & & & Humility influence KS \\
\hline $\begin{array}{c}\text { Dwiwardani et al } \\
(2014)\end{array}$ & & $\sqrt{ }$ & & & Predictors of humility \\
\hline Exline (2008) & & & & $\sqrt{ }$ & Humility challenges \\
\hline $\begin{array}{l}\text { Exline and Geyer } \\
(2004)\end{array}$ & & $\sqrt{ }$ & & & Perceived humility \\
\hline Frostenson (2015) & & & $\sqrt{ }$ & & Humility in context of business \\
\hline Hopkin et al (2014) & & $\sqrt{ }$ & & & $\begin{array}{c}\text { Intellectual humility and religious } \\
\text { beliefs }\end{array}$ \\
\hline Kruse et al (2014) & & $\sqrt{ }$ & & & Humility and gratitude \\
\hline Labouff et al (2015) & & $\sqrt{ }$ & & & $\begin{array}{l}\text { Humble people help more than less } \\
\text { humble ones }\end{array}$ \\
\hline
\end{tabular}




\begin{tabular}{|c|c|c|c|c|c|}
\hline Landrum (2011) & & $\sqrt{ }$ & & & Measuring dispositional humility \\
\hline $\begin{array}{l}\text { Leach and Ajibade } \\
\text { (2016) }\end{array}$ & & & & $\sqrt{ }$ & Predictors of humility \\
\hline $\begin{array}{l}\text { Lee and Ashton } \\
\text { (2004) }\end{array}$ & & $\sqrt{ }$ & & & Honest-Humility as a personality factor \\
\hline $\begin{array}{l}\text { Mallasi and Ainin } \\
\text { (2015) }\end{array}$ & & $\sqrt{ }$ & & & Humility as a non-monetary factor \\
\hline Meagher et al (2015) & & $\sqrt{ }$ & & & Intellectual humility \\
\hline Morris et al (2005) & & & & $\sqrt{ }$ & Humility in leadership \\
\hline $\begin{array}{l}\text { Nielsen and Marrone } \\
(2018)\end{array}$ & & & & $\sqrt{ }$ & Role of humility in organization \\
\hline Nielson et al (2009) & & & $\sqrt{ }$ & & $\begin{array}{l}\text { Humility concept in charismatic } \\
\text { leadership }\end{array}$ \\
\hline Oc et al (2015) & & $\sqrt{ }$ & & & Leader humility in Asian context \\
\hline Ou et al (2014) & & $\sqrt{ }$ & & & $\begin{array}{l}\text { Humble CEO's and empowering } \\
\text { leadership }\end{array}$ \\
\hline Ou et al (2015) & & $\sqrt{ }$ & & & Humble CEO's \\
\hline Owens (2009) & & $\sqrt{ }$ & & & Humility in organizations \\
\hline $\begin{array}{c}\text { Owens and Hekman } \\
\text { (2012) }\end{array}$ & $\sqrt{ }$ & & & & Humble leaders \\
\hline Owens et al (2011) & & & & $\sqrt{ }$ & Humility in organization \\
\hline Peters et al (2011) & & $\sqrt{ }$ & & & Dispositional humility \\
\hline $\begin{array}{l}\text { Prime and Salib } \\
\text { (2014) }\end{array}$ & & & & $\sqrt{ }$ & Humble leaders are best leaders \\
\hline Rowatt et al (2002) & & $\sqrt{ }$ & & & Humility and religion \\
\hline Schein (2013) & & & $\sqrt{ }$ & & Humble Inquiry \\
\hline $\begin{array}{c}\text { Sousa and } \\
\text { Dierendonck (2015) } \\
\end{array}$ & & $\sqrt{ }$ & & & Servant leadership \\
\hline Tangney (2000) & & & $\sqrt{ }$ & & Theoretical perspectives of humility \\
\hline Tangney (2002) & & & $\sqrt{ }$ & & Humility concepts \\
\hline Tangney (2009) & & & & $\sqrt{ }$ & Humility concepts \\
\hline $\begin{array}{l}\text { Vera \& Rodriguez- } \\
\text { Lopez (2004) }\end{array}$ & & & & $\sqrt{ }$ & Humility as competitive advantage \\
\hline $\begin{array}{l}\text { Zhang and Jiang } \\
\text { (2015) }\end{array}$ & & $\sqrt{ }$ & & & Recipient perspective of KS \\
\hline $\begin{array}{c}\text { Zhang and } \\
\text { Sundaresan (2010) }\end{array}$ & & $\sqrt{ }$ & & & Humble knowledge recipient \\
\hline
\end{tabular}

